\title{
Complications of Cerebrospinal Fluid Diversion (Shunt) Catheters: A Pictorial Essay
}

\author{
M. D. Rahalkar ${ }^{1}$ \\ 'Department of Radiology, Sahyadri Hospital, Pune, Maharashtra, \\ India
}

Indian J Neurosurg 2018;7:58-76

\begin{abstract}
Address for correspondence: M. D. Rahalkar, MD, DMRD, FRCR, Department of Radiology, Sahyadri Hospital, 30 C, Erandawane, Karve Road, Pune 411004, Maharashtra, India (e-mail: mdrahalkar@hotmail.com).
\end{abstract}

Abstract
Keywords
- VP shunt
- complications of VP
shunt
- migration of VP shunt
catheters
- slit lateral ventricle
syndrome
- double ventricle
syndrome

Ventriculoperitoneal shunt catheters are very commonly used for hydrocephalus of varying etiologies in infancy to childhood to bypass the obstruction. Few people are aware of their complications, such as infection, obstruction, malfunctioning, displacements, fluid collections, disconnections, and entry into various intra-abdominal organs. These complications and related literature and images are presented in this essay. In some cases, a radiologist can be of use to a neurosurgeon to alert what complication a given catheter has produced. The objectives are (1) to describe the types and functioning of cerebrospinal fluid diversion shunt catheters, (2) to know what can go wrong with the position and function of these catheters, and (3) to understand the specific or syndromic states of complication.

\section{Introduction}

Hippocrates (5th century B.C.), the father of medicine, is thought to be, in fact, the first physician to attempt and document the treatment of hydrocephalus. He is often cited as the first to have performed ventricular punctures. The clinical or surgical management of hydrocephalic or obstructed cerebrospinal fluid (CSF) pathways in children was a great challenge for neurosurgeons before CSF diversion techniques were made available about a century ago. After several trials of ventricular puncture, external CSF drainage, and ventriculostomy, reasonably good ventriculoperitoneal shunts (VPSs) were introduced by 1949. Much later on, new generation of devices such as autoregulating, antisiphon, and gravitational valves were developed. By 2014, at least 127 different designs of such catheters were available. ${ }^{1}$ The statistics claims that 69,000 admissions in U.S. hospitals were for VPS surgeries. ${ }^{2}$

It was possible to improve life expectancy or standard of life after using these shunts in the case of millions of children. However, shunting does produce many complications, which assume a part of neurosurgeons' work, up to $5 \%$ of operations (personal experience of our staff neurosurgeons). These unique problems are collected over a period of long time and presented in the light of literature here in this pictorial essay.

\section{Types of Cerebrospinal Fluid Diversion Shunts}

The shunt catheters that are commonly used to divert CSF from dilated/obstructed ventricles are (1) VP, (2) cystoperitoneal, (3) ventriculopleural, or (4) ventriculoatrial. Only VPS catheters are described here. There are mainly two types of shunt: one with fixed pressure valve and the other with variable pressure valve.

- Chhabra type (fixed pressure valve): The ventricular end connects with either the lateral ventricle, fourth ventricle, or a cyst. The parts are ventricular end, connector $(16.3 \mathrm{~mm})$, chamber or valve (containing a spring valve), and peritoneal end with a slit valve. This catheter depends on different mechanisms in the valve to regulate the flow of CSF based on a predetermined pressure setting. received

September 1, 2016 accepted after revision

October 18, 2016

published online

November 6, 2017
DOI https://doi.org/

10.1055/s-0037-1599786. ISSN 2277-954X.
Copyright (C2018 Neurological

Surgeons' Society of India
License terms

$($ () (1) $\odot \circledast$ 
- Codman Hakim shunt (DePuy Synthes): The special feature is that it is a programmable device, which has a metallic dial with pressure readings from 0 to $200 \mathrm{~mm}$ of water. It can be altered externally with the help of a magnetic device according to the clinical requirement. Increasing the pressure reduces the flow across the catheter and vice versa, without the need of another surgical procedure.

- A valve mechanism regulates differential pressure or controls flow through the shunt tubing.

- Peritoneal end: This runs under the skin through tunnel and directs CSF from the valve to the peritoneal cavity, heart, or other suitable drainage site.

- Chambers are used for CSF sampling or injecting medications, as on/off devices, antisiphon, or other flow-compensating devices.

VPSs are likely to require replacement after several years, especially in small children. The average lifespan of an infant's shunt is 2 years. Adults and children over the age of 2 years may not need a shunt replacement for 8 or more years. Shunts systems require frequent monitoring and follow-up. As the pressure of CSF inside the brain increases, the one-way valve opens and the excessive fluid drains to the downstream cavity.

\section{Imaging for Ventriculoperitoneal Shunts}

It is interesting to note that there is a greater reliance on computed tomography (CT) and volume-rendering technique images to effectively understand the complications of VPS. A study by the University of Kentucky in 2012 mentioned that $5.33 \%$ of shunted hydrocephalic children underwent CT. One child had even $34 \mathrm{CT}$ scans from birth to 4 years of age, though steps were taken to keep radiation dose minimal. Similar studies had shown that CT was resorted to in hydrocephalic children for shunt-related problems in 2 to 13.4 of cases\%. ${ }^{1}$

\section{Shunt Malfunctions}

Incidence of shunt malfunctions ${ }^{3}$ was recorded up to $50 \%$ in first year of life and up to 4 to $5 \%$ per year thereafter, and as high as $81 \%$ after 12 years. ${ }^{2}$

- Shunt infection: This is found in approximately $25 \%$ of cases in infants younger than 6 months, though the risk has decreased in recent years. Infection is due to Staphylococcus epidermidis, which is normally found on the surface of the person's skin, the sweat glands, and hair follicles deep within the skin or secondary to abdominal infection.

- Shunt obstruction: causes-high protein, blood, and infection. Approximately $50 \%$ of shunt complications occur in pediatric series. A weird cause of obstruction was reported from the subcontinent as a dead roundworm, which caused obstruction and infection in the neck. ${ }^{4}$

Symptoms include headache, vomiting, lethargy, ataxia, nausea, obtundation, bulging fontanelle, and increased head circumference.

\section{Treatment}

If block is seen, pumping of the reservoir is performed. Peritoneal end is first checked and then proximal connections are checked. Revision of shunt to another similar shunt or new type of shunt is employed. In approximately 50 to $70 \%$ of cases, multiple revisions are required. Sometimes, the ventricular end gets disconnected and left abandoned inside the skull, and a new active shunt is placed. Accessory devices may be added, such as an antisiphon device attached in-line with the valve to minimize overdrainage of CSF when a patient stands up.

Here is the importance of imaging. There are innumerable wrong things that can happen to the catheter or its function. A shunt X-ray series and CT are important tools in management. X-ray series consists of radiographs of skull lateral/ neck, chest, and abdomen. CT or magnetic resonance imaging (MRI) may also be required.

\section{Complications of Shunt in the Brain and Neck}

The normal distance between cranial and peritoneal ends of catheter should be approximately $5 \mathrm{~mm}$ corresponding to the gap between ends of catheters sleeved over the connector tube, and the chamber should be seen as a tubular radiolucent structure below it (-Fig. 1). If the distance is $16 \mathrm{~mm}$ (length of the connector) or more, disconnection should be suspected ( - Fig. 2 and $\boldsymbol{- T a b l e ~} \mathbf{1}$ ). A brief discussion on these complications is as follows.

Disconnection of ventricular or peritoneal ends from the connector tube at the burr hole $(\boldsymbol{- F i g}$. 3 ) or beyond the burr hole ( - Fig. 4). Disconnection may occur at any site of connection along the course of the tubing. Shunt disconnection or fracture

Table 1 Complications

\begin{tabular}{|l|l|}
\hline 1 & $\begin{array}{l}\text { Disconnection of ventricular or peritoneal ends } \\
\text { from the connector tube }\end{array}$ \\
\hline 2 & $\begin{array}{l}\text { Fluid collections near the burr hole (called as CSF } \\
\text { varix) or along the shunt tract }\end{array}$ \\
\hline 3 & $\begin{array}{l}\text { Calcification may occur within the catheter tract } \\
\text { or around the shunt }\end{array}$ \\
\hline 4 & Thickening of skull bones \\
\hline 5 & Formation of septa in ventricles/cyst \\
\hline 6 & Subdural hemorrhage with/without calcification \\
\hline 7 & $\begin{array}{l}\text { Gliosis or hemorrhage along the shunt tract or } \\
\text { in the ventricles }\end{array}$ \\
\hline 8 & $\begin{array}{l}\text { Long-term shunting may induce pneumosinus } \\
\text { dilatans or tonsillar herniation }\end{array}$ \\
\hline 9 & Reverse herniation of cerebellum after VP shunt \\
\hline 10 & $\begin{array}{l}\text { Proximal migration of shunt catheter into the } \\
\text { skull }\end{array}$ \\
\hline 11 & $\begin{array}{l}\text { Intraparenchymal cyst following prolonged VP } \\
\text { shunt }\end{array}$ \\
\hline 12 & Recoiling or knotting of catheter \\
\hline
\end{tabular}

Abbreviations: CSF, cerebrospinal fluid; VP, ventriculoperitoneal. 

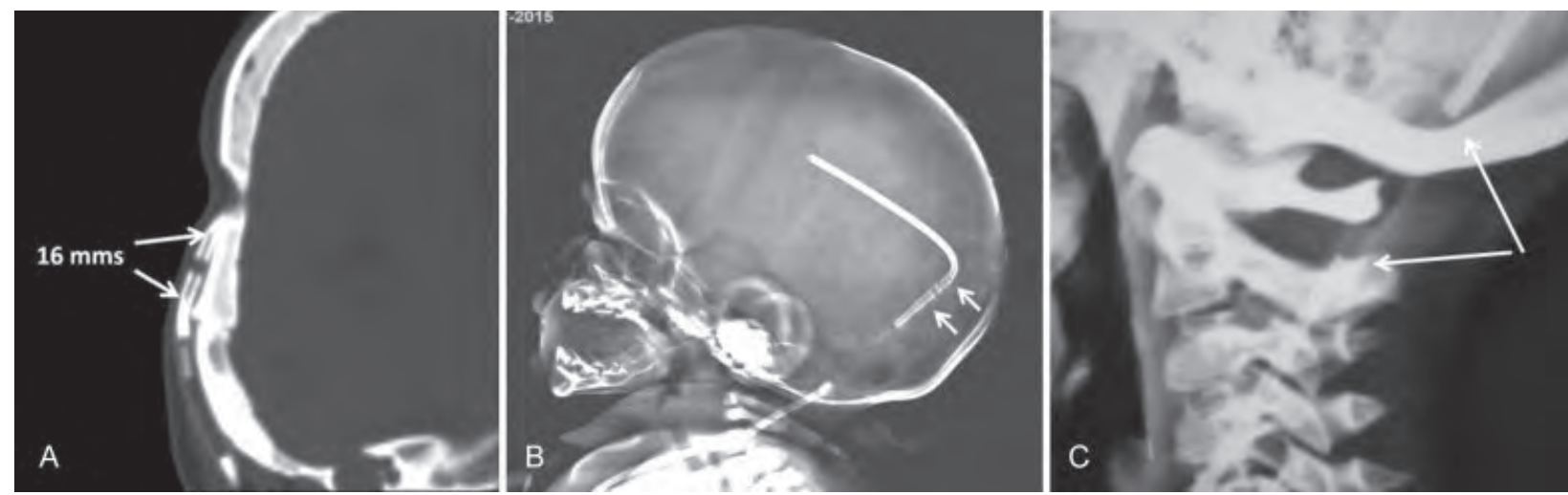

Fig. 1 (A, B) The normal gap between ventricular and peritoneal ends measuring approximately $5 \mathrm{~mm}$ after both ventricular and peritoneal ends are sleeved over the connector (marked by arrows), which measures $16 \mathrm{~mm}$. (C) The normal appearance of chamber of the shunt tube (between the arrows) in a different child.

constitutes the second most frequent cause of mechanical shunt malfunction. Disconnection is defined as a loss of continuity of the shunt at connecting points between catheters, valves, and/ or connectors, whereas fracture is an actual breakage of the catheter with separation between the segments.

Fluid collections near the burr hole (called as CSF varix) or along the shunt tract, which can be called as a CSFoma

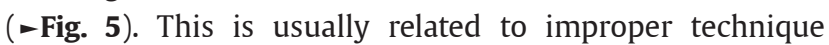
(loose ligature) or excessive strain along the shunt tube between two points of fixation.

Both these complications are likely due to improper technique (loose ligature) or excessive strain along the shunt tube between two points of fixation. The incidence of disconnection has been decreased by the introduction of one-piece shunts.

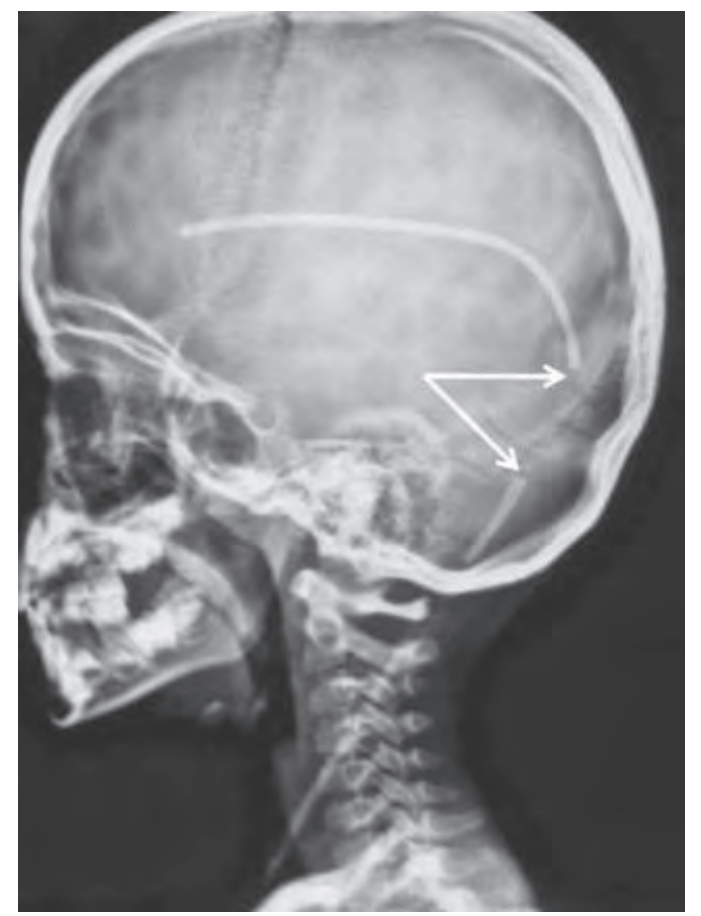

Fig. 2 Distance between ventricular and peritoneal ends measured $3.7 \mathrm{~cm}$ (between arrows) and therefore disconnection was diagnosed. This was corrected surgically.
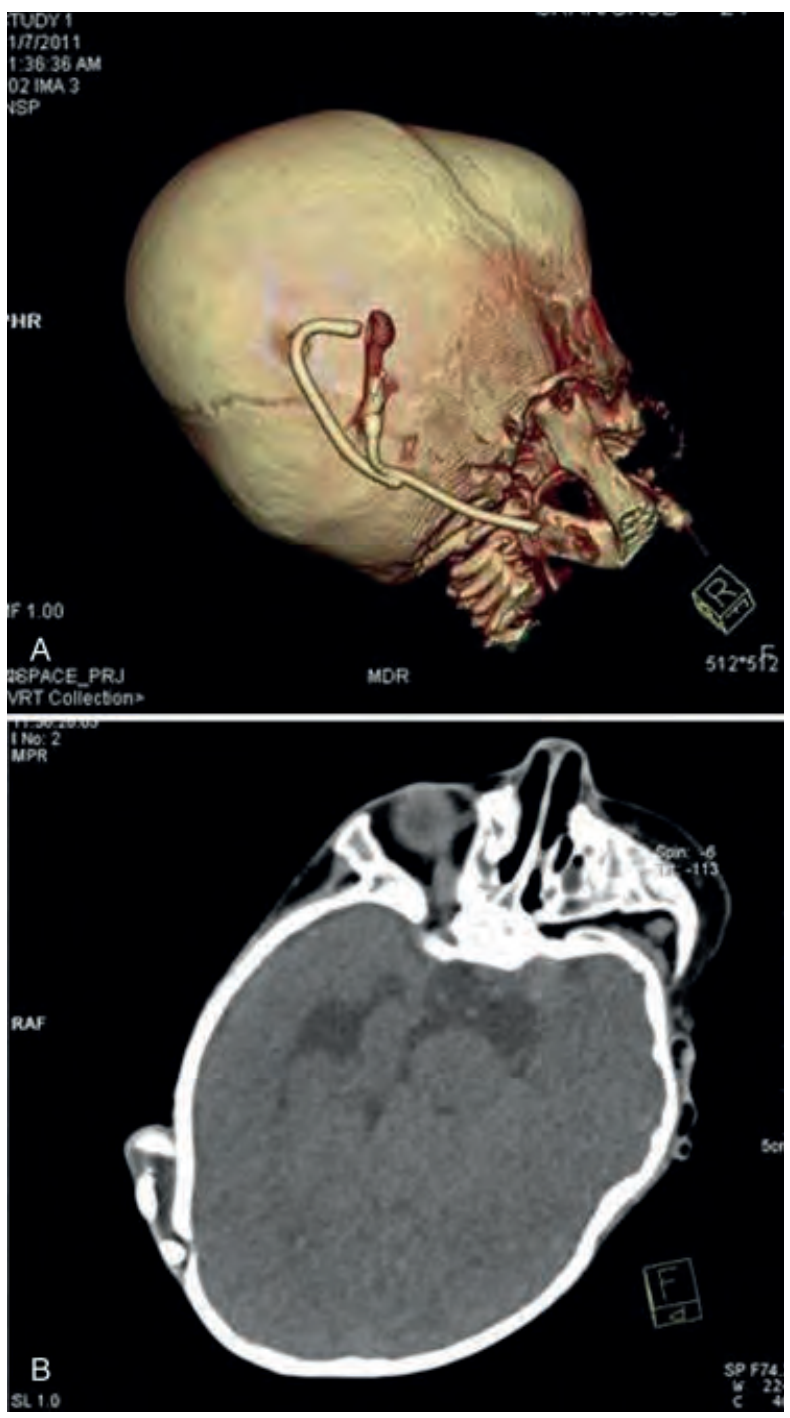

Fig. 3 (A, B) There is disconnection of both ends of catheters at the burr hole, which are lying just outside the skull. The child had signs/symptoms of shunt malfunction. The whole ventricular catheter is seen at the burr hole. 

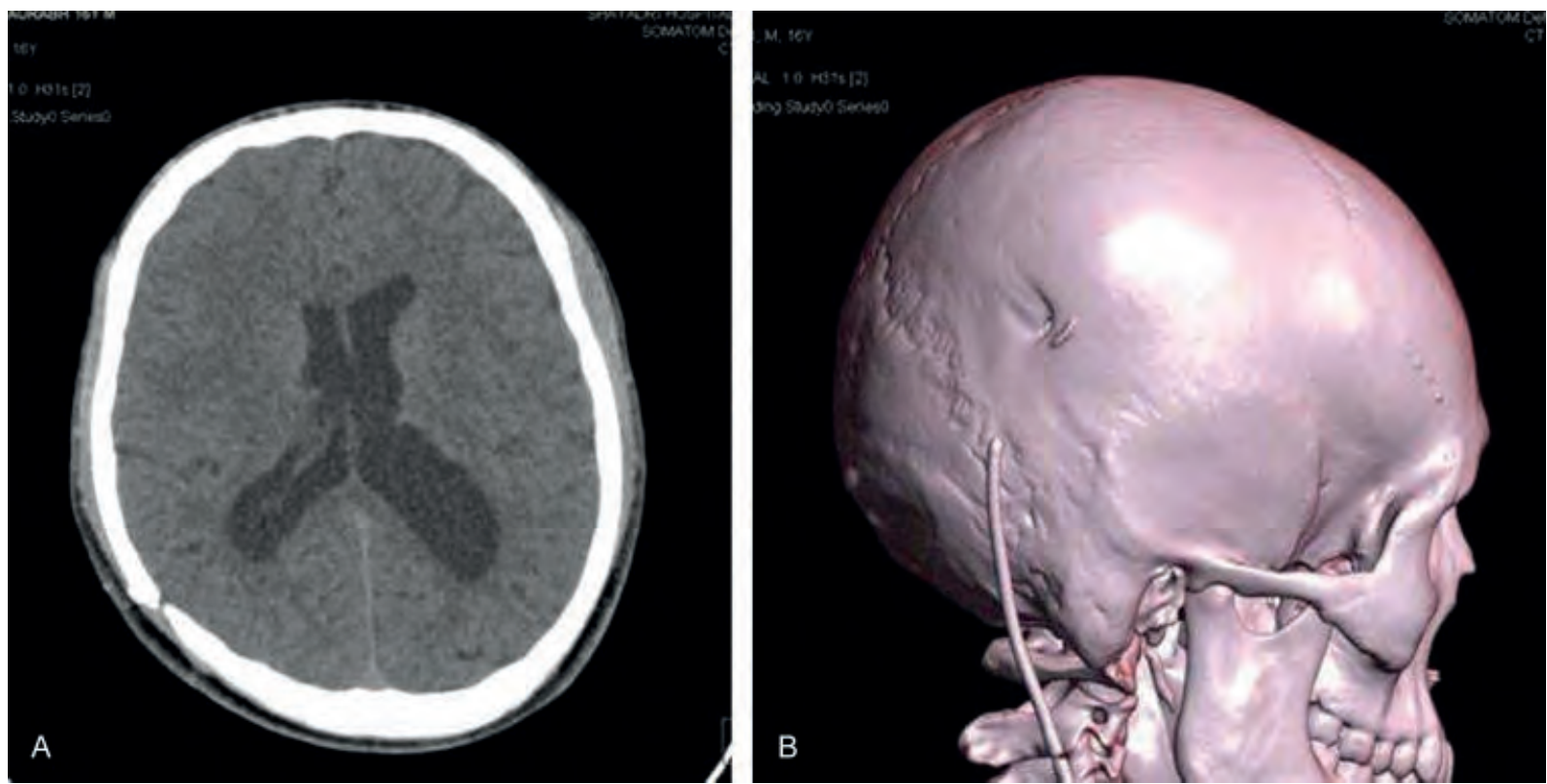

Fig. 4 (A, B) This male, now 16 years of age, was shunted at 6 months' age. He had a sudden sensation of something slipping in the neck. Computed tomography has shown complete pulling out of the shunt, which was lying in the neck.

Calcification may occur within the catheter tract or around the shunt. ${ }^{6}$ A few factors about calcification along the tract or around the catheter as per this article are as follows: it may be dystrophic, it may cause malfunction of catheter, degradation of silicone material may induce calcification, and it may depend on quality of silica or rubber (-Fig. 6).

Thickening of skull bones ( $\boldsymbol{- \text { Fig. }}$ 7). Progressive slow collapse of ventricles may induce such a phenomenon. The diffuse thickening of the skull can be due to centripetal migration of the inner table. The calvarial thickness may even double that of a normal skull appropriate for that age. The eyes may look sunken due to altered shape or molding of the anterior skull fossa.

Formation of septa in ventricles/cyst following CP shunt ( - Fig. 8) is known to occur. Hemorrhage or infection in ventricles may induce such septa.

Gliosis or hemorrhage may take place along the shunt

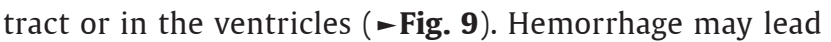
to gliosis along the shunt tube treat. Hemorrhage can occur in parenchyma, ventricles, or subdural space. This may result from injury to choroid plexus, friability of tissue, repeated attempts of puncture, occlusion of veins, or coagulopathy.
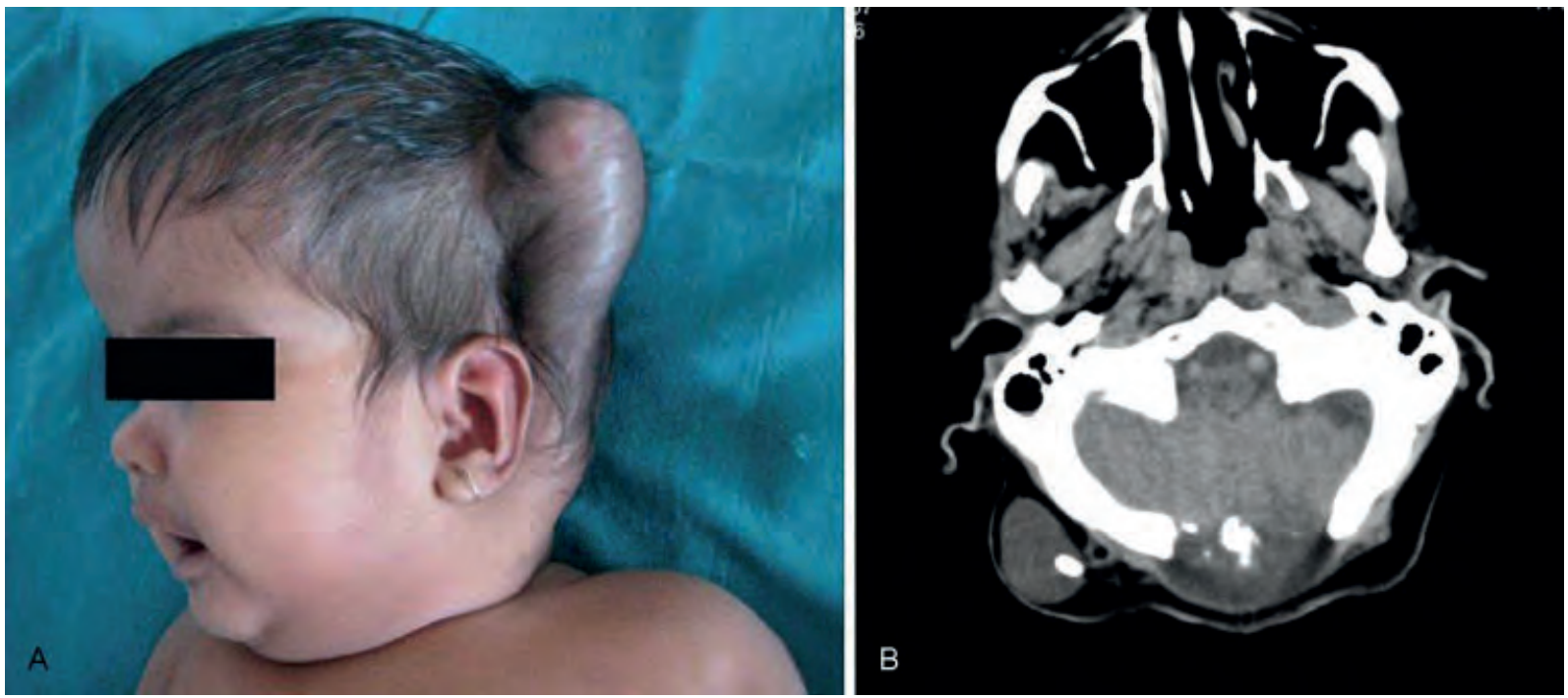

Fig. 5 (A) Fluid collection just outside the burr hole is described as varix. (Used with thanks and permission from Ahmed A.) $)^{5}$ (B) A swelling in this child also shows a round fluid density mass around the catheter just outside the occipital burr hole described as CSFoma. 


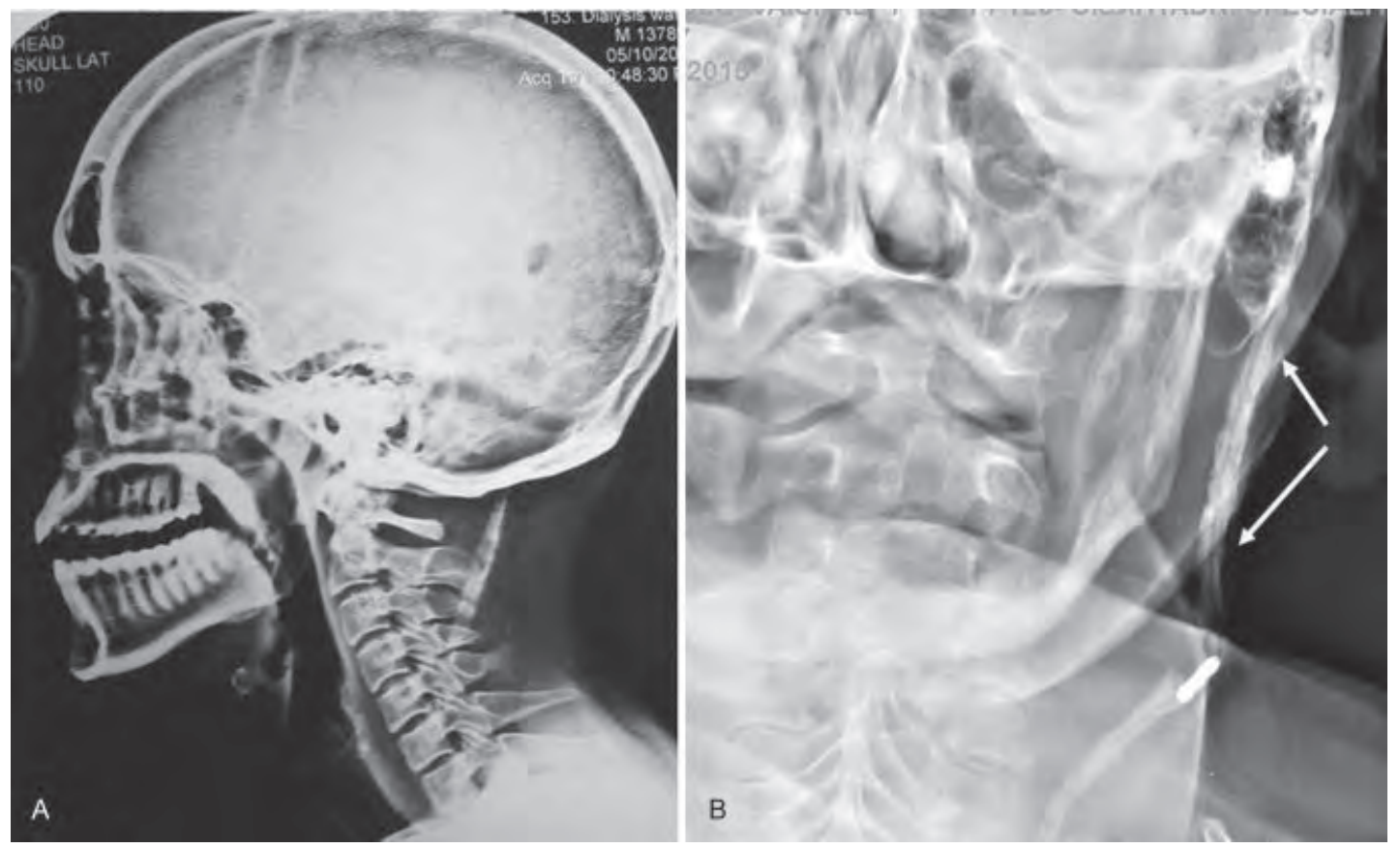

Fig. 6 (A) In this adult, shunt catheter was removed a few years ago. A hard swelling was felt in the neck, which corresponded to tubular calcification within the track in the neck. (B) This 66-year-old female had a ventriculoperitoneal catheter since 40 years for hydrocephalus due to meningitis. As she complained a hard swelling along the catheter in the neck since a few weeks, a radiograph was taken. It shows calcification around the catheter between the arrows. In both cases, the neurosurgeon thought that no intervention was needful.

Subdural hemorrhage with/without calcification may also result from long-standing shunting ( - Fig. 10). Calcification takes place over the medial aspect of any chronic subdural hematoma, and post-VPS skull is no exception. This has been called as armored brain.

Long-term shunting may induce pneumosinus dilatans or tonsillar herniation.

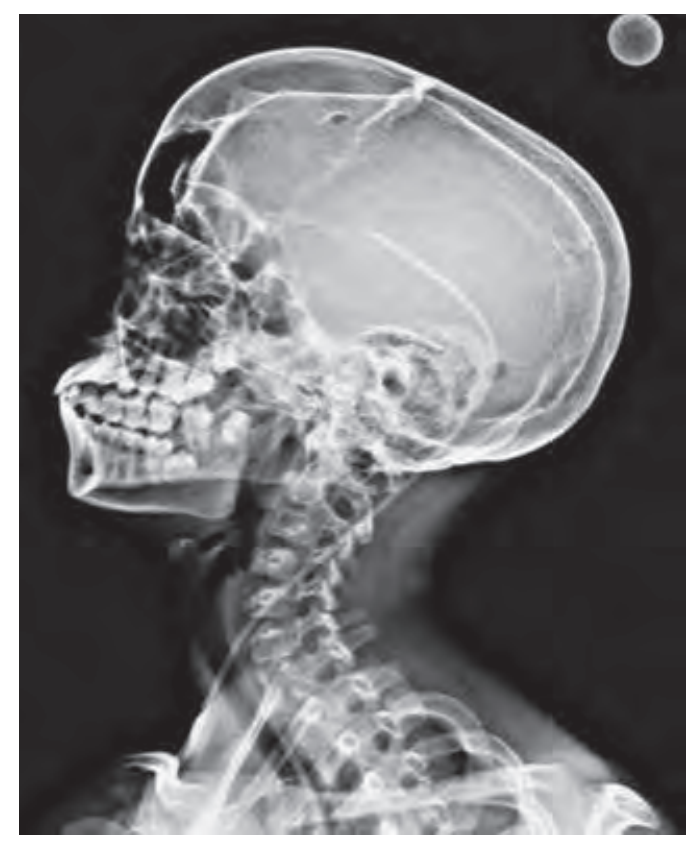

Fig. 7 Thickening of skull bones is seen after a prolonged use of ventriculoperitoneal (VP) shunt. In this child with a congenital cyst, a VP shunt was placed to decompress the obstructed ventricles.

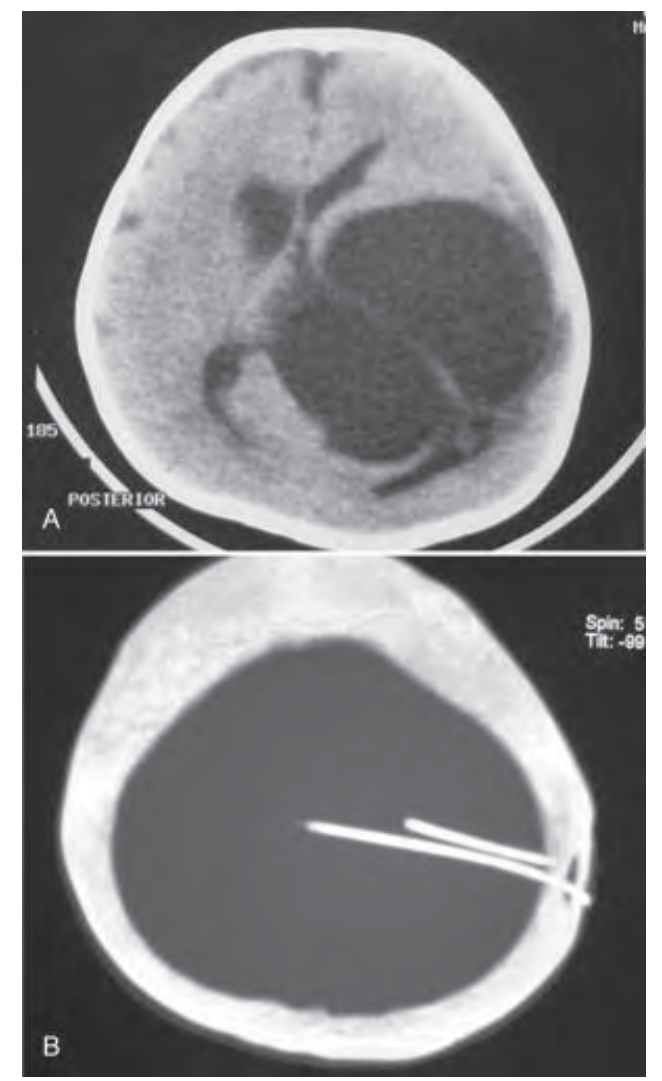

Fig. 8 (A) In this child with a congenital cyst, a ventriculoperitoneal shunt was placed to decompress the obstructed ventricles. (B) A few septa and thickening of skull tables developed as shown on the computed tomography along with a segment of previous shunt left behind in the skull. 


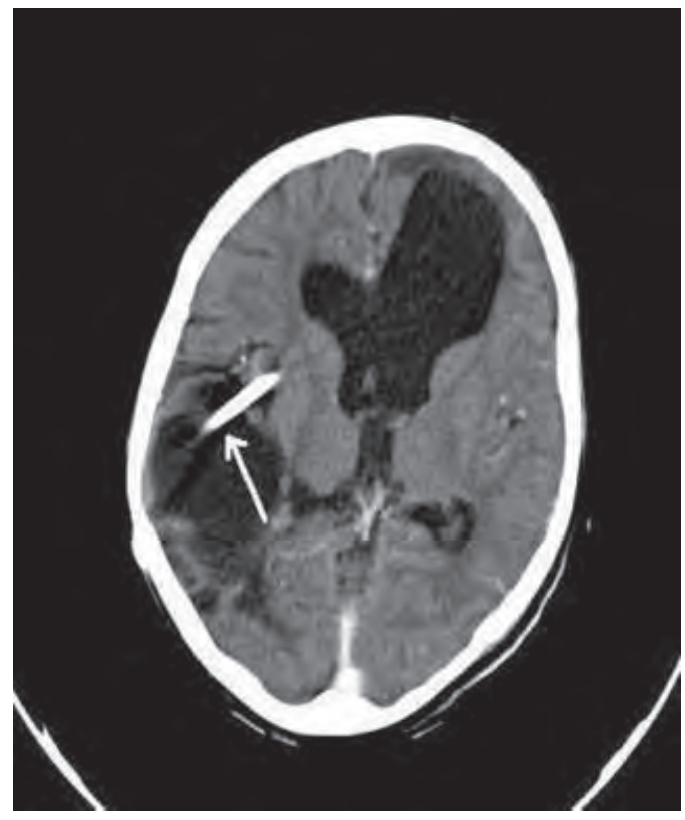

Fig. 9 A focal hypodensity seen along the track of shunt catheter is often seen like in this image. (Used with thanks and permission from Jakhere SG. $)^{12}$

Reverse herniation of cerebellum after VPS happens very rarely, when ventricles decrease in size following VPS. The cerebellum herniates upward as a result.

Proximal migration of shunt catheter into the skull may happen, though seen in only 0.1 to $0.4 \%$ of all cases ${ }^{7}$ (-Fig. 11). The entire catheter is pulled back proximally into the cranium. The causes are as follows:
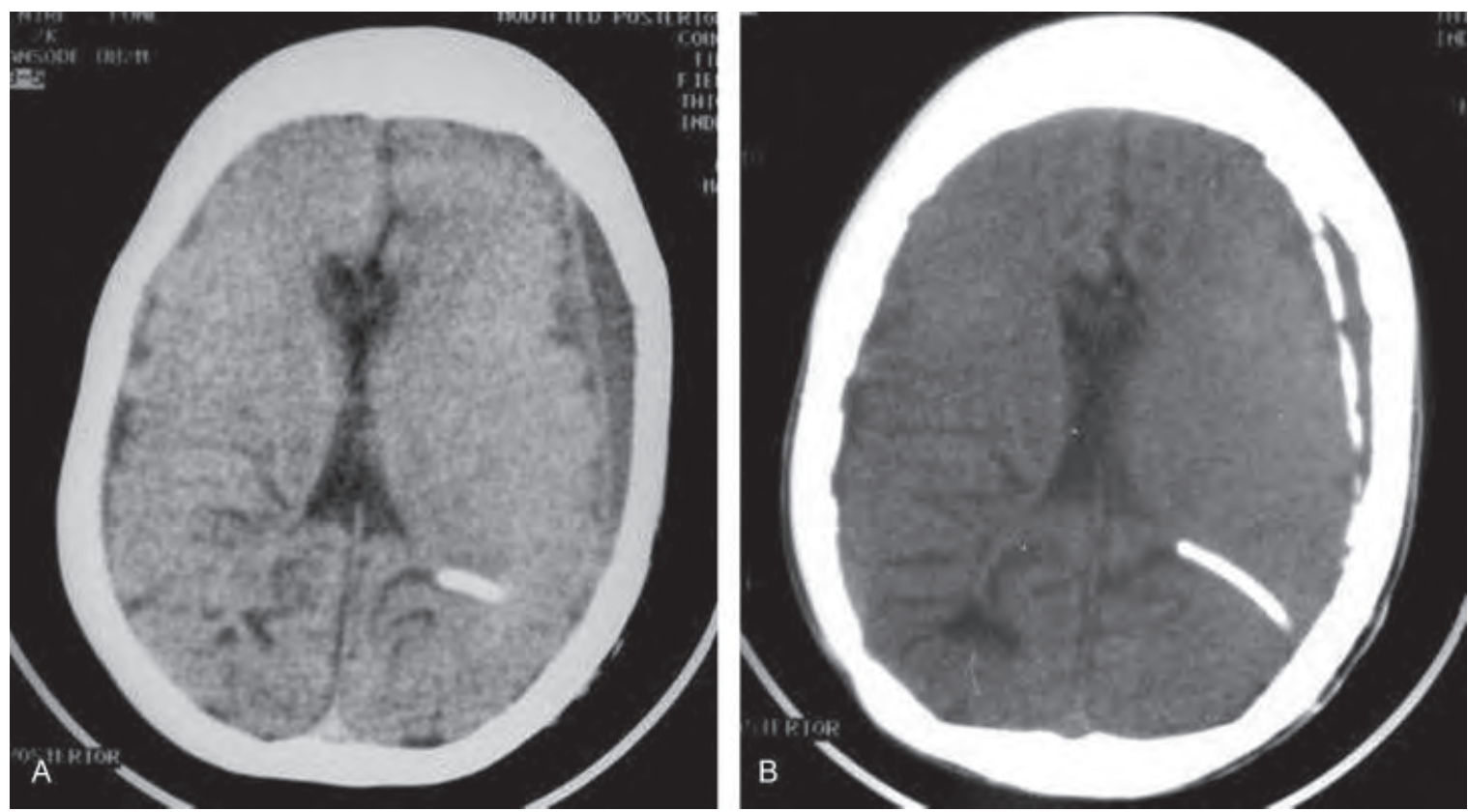

Fig. 10 (A) This child, previous computed tomography (CT) had shown development of bilateral subdural effusions (left). (B) The shunt was revised in 2002, and CT done in 2003 had shown calcification of medial wall of left subdural effusion.
- Excessive neck movements producing a windlass effect.

- Large potential subgaleal space created for chamber positioning.

- Dilated ventricles with negative suctioning pressure.

- A positive intra-abdominal pressure.

- Younger age and thin cortical mantle.

- Surgical technicality of creating a large burr hole, wide dural opening, and nonanchoring of chamber to pericranium.

- Short distance between ventricular and abdominal end seen in young patients, and severe hydrocephalus.

- Peritoneal adhesions with local cyst formation, nonabsure causing migration of the tube along the fibrous tract of the tunnel or due to child outgrowing peritoneal tubing.

Only a few cases of intraparenchymal cyst following prolonged $\mathrm{VPS}^{8}$ have been reported ( - Fig. 12). If the tip of VPS catheter protrudes beyond the walls of frontal horns, and the shunt is blocked, a cystic collection of CSF can occur in the parenchyma, which can be surrounded by extensive vasogenic edema. It can also occur along and surrounding the catheter in its tract in the parietooccipital lobe.

Recoiling (producing a fish-hook appearance) or knotting of catheter can occur. It is feared that such position of tip of catheter would make thrombosis vulnerable and revision is considered necessary. sorption of CSF, and constant positive abdominal pres- 

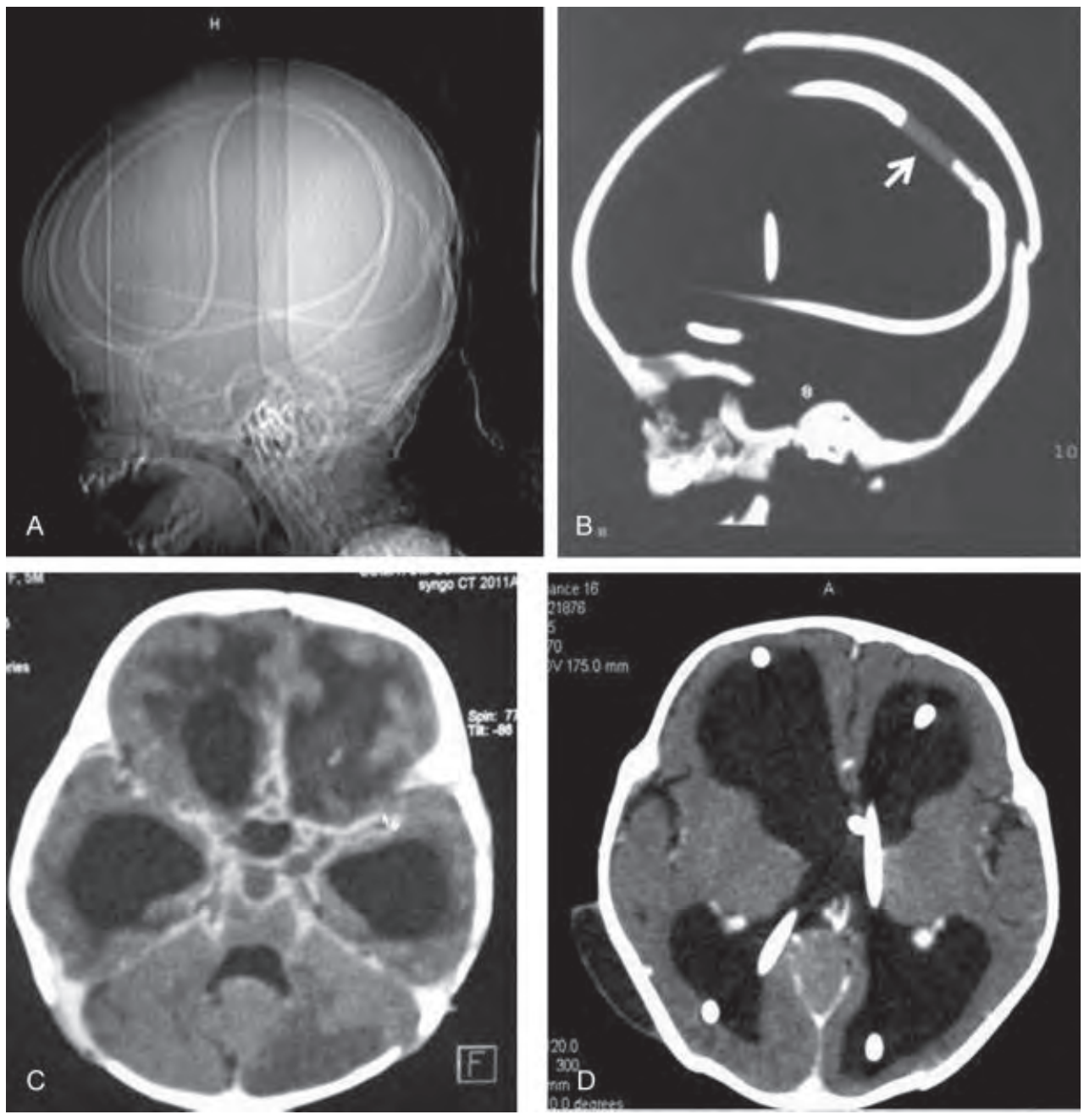

Fig. 11 (A-D) Lateral radiograph and computed tomography (CT) images of this female child with missing ventriculoperitoneal shunt and new symptoms of headache, fever, and vomiting. There is total intracranial migration of the shunt catheter including its chamber (arrow). Contrast CT shows enhancement of basal cisterns to suggest meningitis. The axial sections showed too many cross-sections of the catheter.

\section{Thoracic Complications of Ventriculopleural Shunt}

The complications are listed as follows:

- Effusion (-Fig. 13): this is very rare to occur. In this case, it might be a sympathetic or reactionary response.

- Bronchocutaneous fistula: this may result from injury to the lungs, as shown in in - Fig. 14. This is very rare indeed and, in this case, must have happened due to injury to the bronchus during recoiling of VPS from the abdomen to the thorax. Pneumothorax, surgical emphysema, and pneumonia (-Fig. 15) may also occur.

\section{Abdominal Complications}

These have been presented in - Table $\mathbf{2}$ and are discussed in short in the following ${ }^{9}$ :

Piercing of diaphragm causing an effusion. ${ }^{10}$ It is not common, but the tip of peritoneal catheter may pierce the
Table 2 Abdominal complications

\begin{tabular}{|l|}
\hline Piercing of diaphragm \\
\hline Pneumoperitoneum due to bowel perforation \\
\hline Intestinal obstruction due to peritoneal adhesions \\
\hline $\begin{array}{l}\text { Acute ascites or bowel perforation by a retained } \\
\text { fragment }\end{array}$ \\
\hline Formation of an intraperitoneal pseudocyst \\
\hline $\begin{array}{l}\text { Fractures/disconnections ( }- \text { Fig. } 22 \text { ) or knotting of } \\
\text { catheter }\end{array}$ \\
\hline Subcutaneous fluid collections \\
\hline $\begin{array}{l}\text { Wandering or recoiling of catheter into subcutaneous soft } \\
\text { tissues }\end{array}$ \\
\hline Vagabond catheters \\
\hline Retrograde spread of infection to the brain \\
\hline $\begin{array}{l}\text { Antegrade spread of malignant cells from brain tumor to } \\
\text { peritoneal cavity }\end{array}$ \\
\hline
\end{tabular}



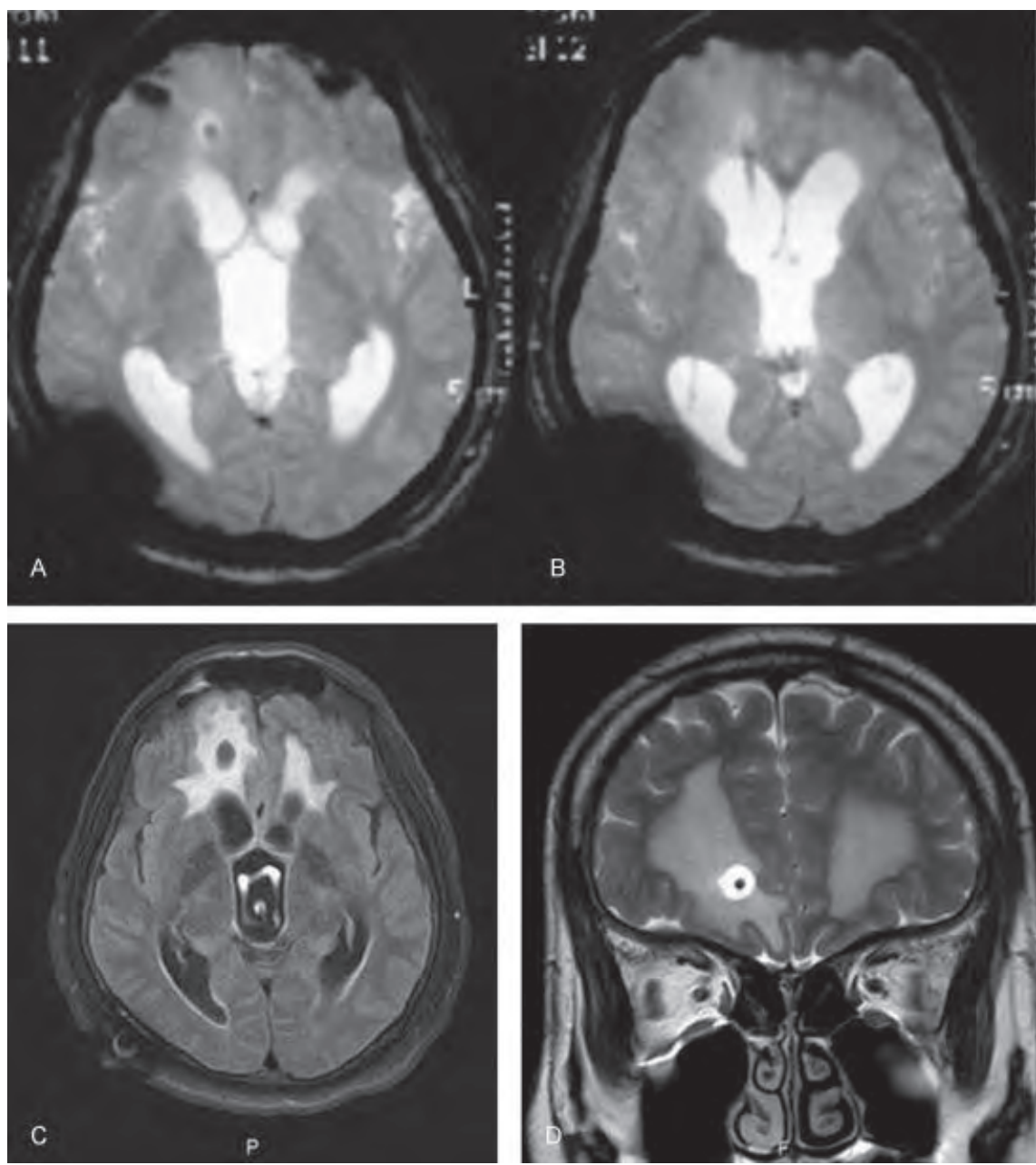

Fig. 12 In this male, now 16 years of age, ventriculoperitoneal shunt was employed since the age of 5 years. Magnetic resonance imaging showed tip of the shunt catheter protruding into the right frontal lobe. A cerebrospinal fluid intensity cyst is formed around it. Even larger cysts around the catheter can occur and these should not be mistaken for abscesses. (A,B) Gradient echo, (C) fluid-attenuated inversion recovery, and (D) T2-weighted images.

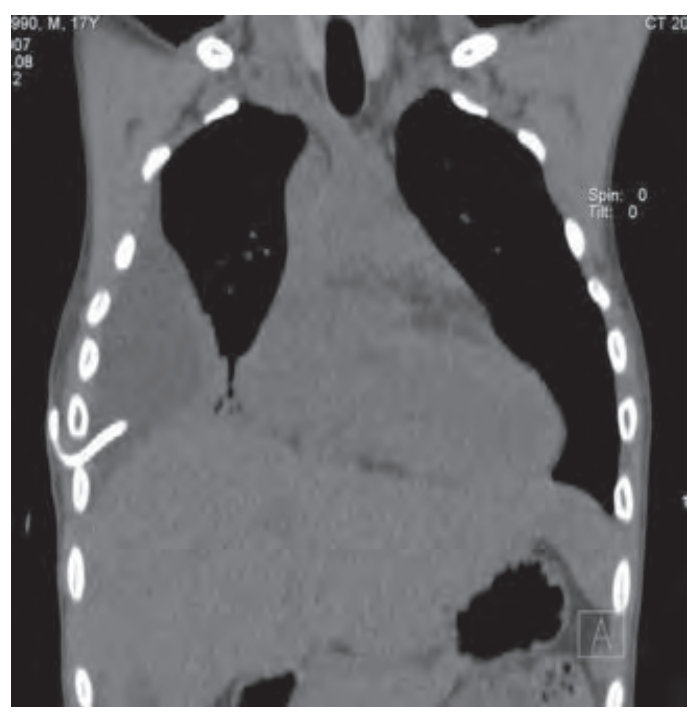

Fig. 13 Normally after ventriculopleural shunt is placed, there is no effusion, but in this child, a moderately large effusion developed.
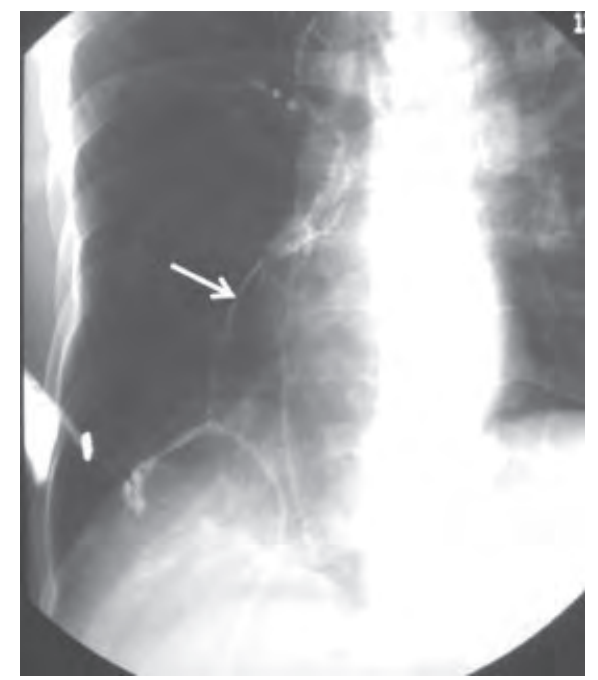

Fig. 14 In this case, the tip of peritoneal catheter recoiled in the soft tissues of the thorax and produced a bronchocutaneous fistula, which has been opacified. The track of the fistula has been marked by an arrow. The only plausible explanation may be that the catheter tip must have traumatized the lung on its way while appearing in the subcutaneous tissues (Used with permission from Pai B, Mumbai.) 


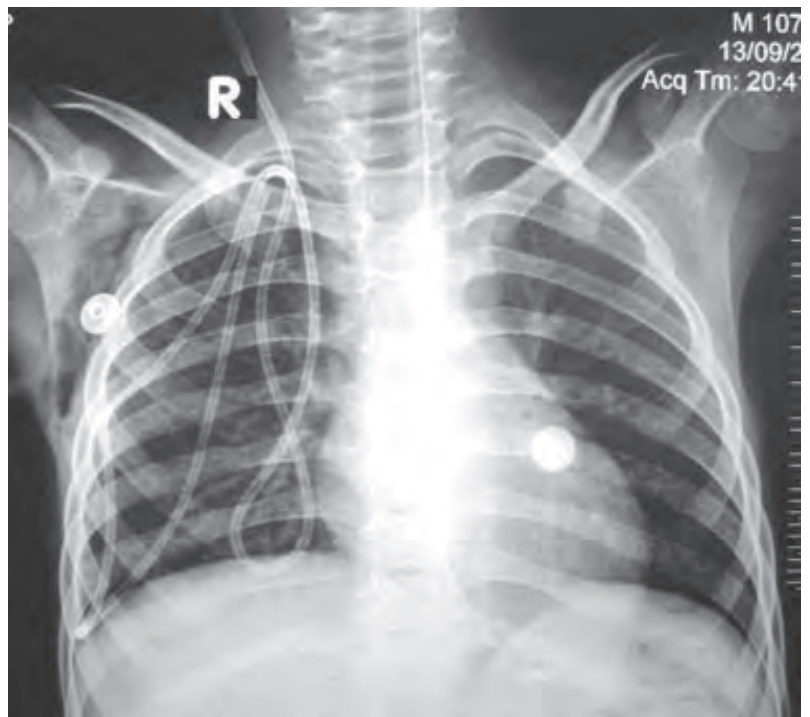

Fig. 15 After ventriculopleural shunt procedure, pneumothorax and surgical emphysema of right chest wall resulted in this child.

diaphragm into the lungs, as has been reported. A surgical intervention would be required to remove it.

Pneumoperitoneum may occur due to bowel perforation or simply due to air entering into the abdominal cavity during the procedure ( - Fig. 16).

Intestinal obstruction occurs due to peritoneal adhesions ( - Fig. 17). This can be explained by irritation of the peritoneum by the shunt catheter over a long period of time.

Acute ascites ( $\boldsymbol{- F i g . 1 8}$ ) or bowel perforation by a retained fragment of the catheter is a well-known complication (-Fig. 19). It is not clear why in a few cases acute ascites/ effusion develops after VP or VPS procedure. It may be that

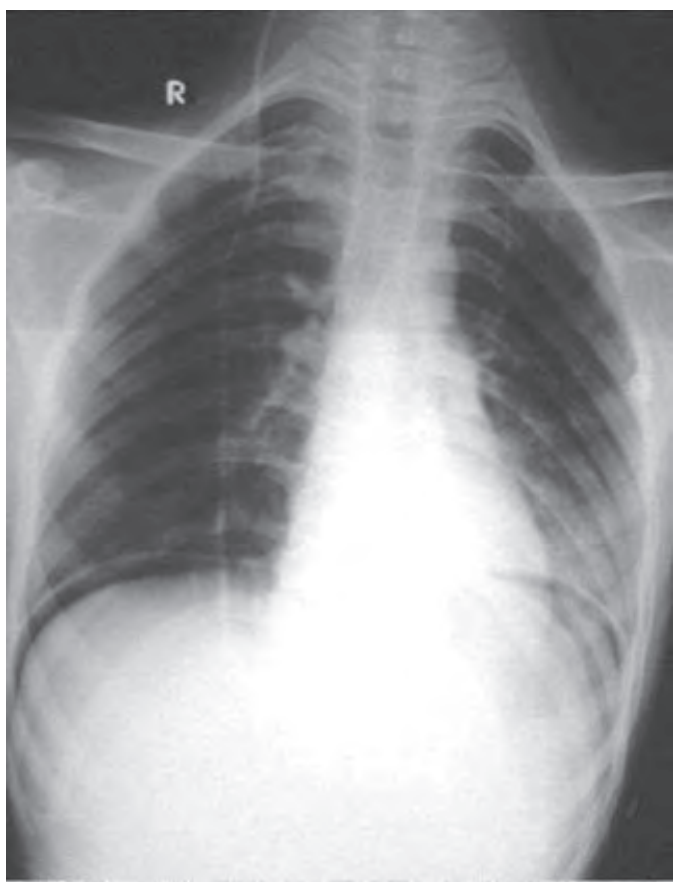

Fig. 16 Pneumoperitoneum developed in this child after placement of a peritoneal catheter.

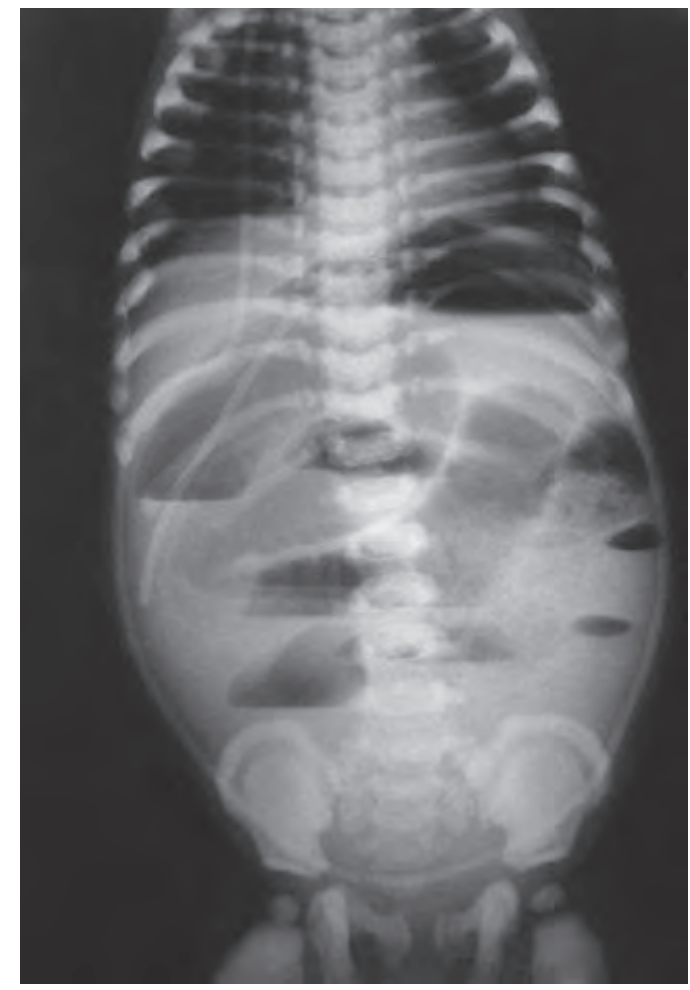

Fig. 17 This child with osteopetrosis had aqueduct stenosis, for which a ventriculoperitoneal shunt was performed in infancy. The child developed diffuse peritoneal fibrosis causing intestinal obstruction. The catheter is seen coursing along the boundary of peritoneum.

the body may not cope with drainage of extra fluid or it may be rarely due to infection.

Formation of an intraperitoneal pseudocyst, as discussed in Wang et $\mathrm{al}^{11}$ (-Figs. 20 and $\mathbf{2 1}$ ), fractures or disconnec-

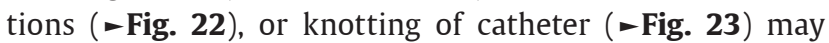
occur. The associated factors for broken shunts are growth spurts, aging, brittle or partially calcified shunt, multiple proximal revisions, local trauma to shunt, athletic activity without history of direct trauma, and postscoliosis correction.

Subcutaneous fluid collections (pseudocysts) may occur due to leakage of CSF around the catheter into the soft tissues (-Fig. 24). The exact cause is not known. Local infection/ peritonitis, disturbance of absorption of peritoneal fluid, increased CSF flow, and so on may cause CSF to be collected and walled-off to form a pseudocyst.

Wandering or recoiling of catheter into subcutaneous soft tissues of thorax, abdominal wall, or behind breast ${ }^{12}$ (-Fig. 25). If the tip happens to lie behind the breast, it may form and simulate a cystic mass. Mammograms and ultrasonography may give a clue by observing a tubular structure in the cyst.

Vagabond catheters: they may go anywhere and enter in any tubular structure and present themselves such as:

- Perforate bladder and extrude through urethra ${ }^{13}$ (-Fig. 26).

- Protrude through vagina ${ }^{14}$ ( - Fig. 27). 

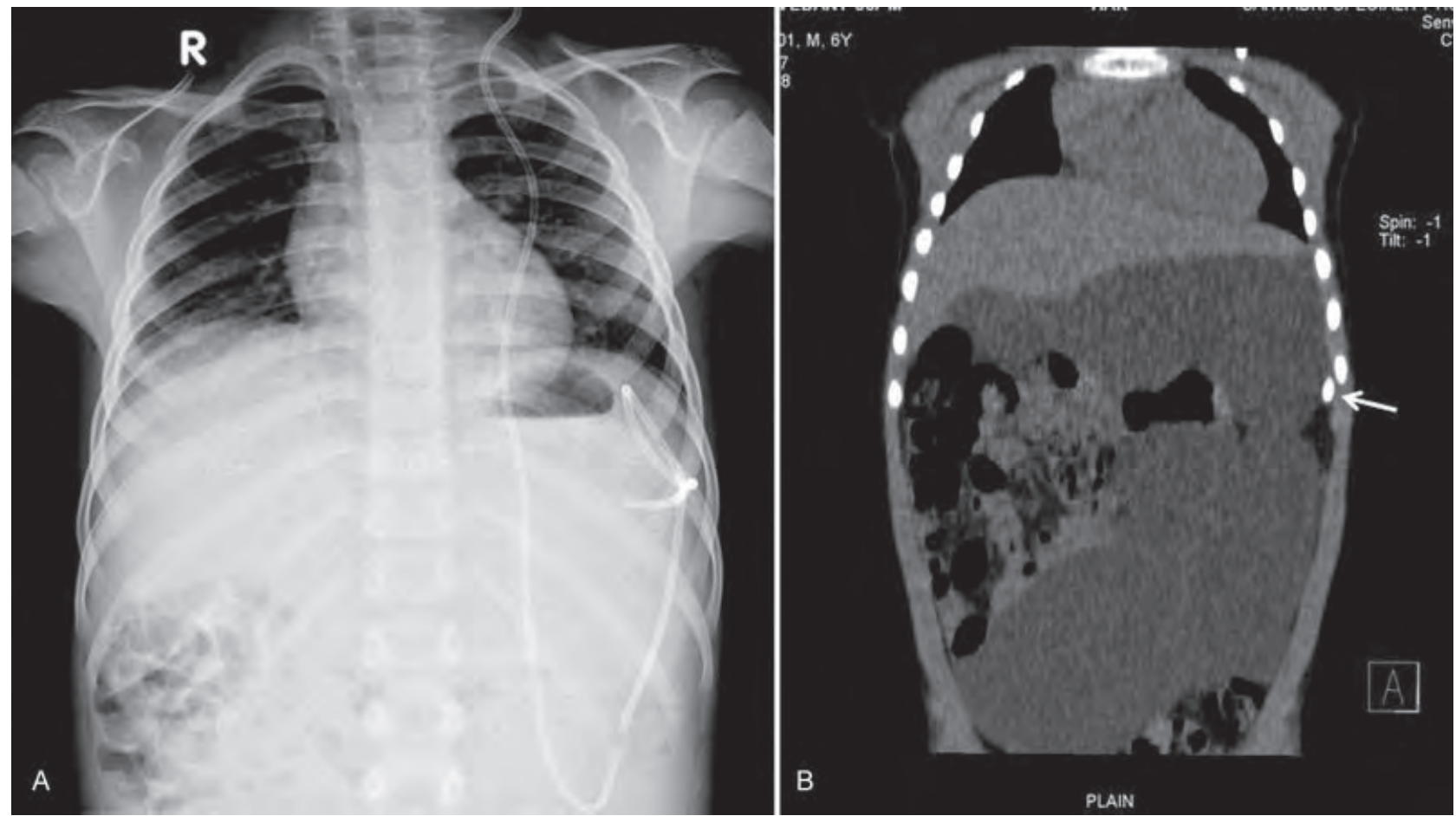

Fig. 18 (A, B) This male child had a massive acute ascites following ventriculoperitoneal shunt due to sympathetic reaction. The arrow points to the section of the peritoneal catheter.
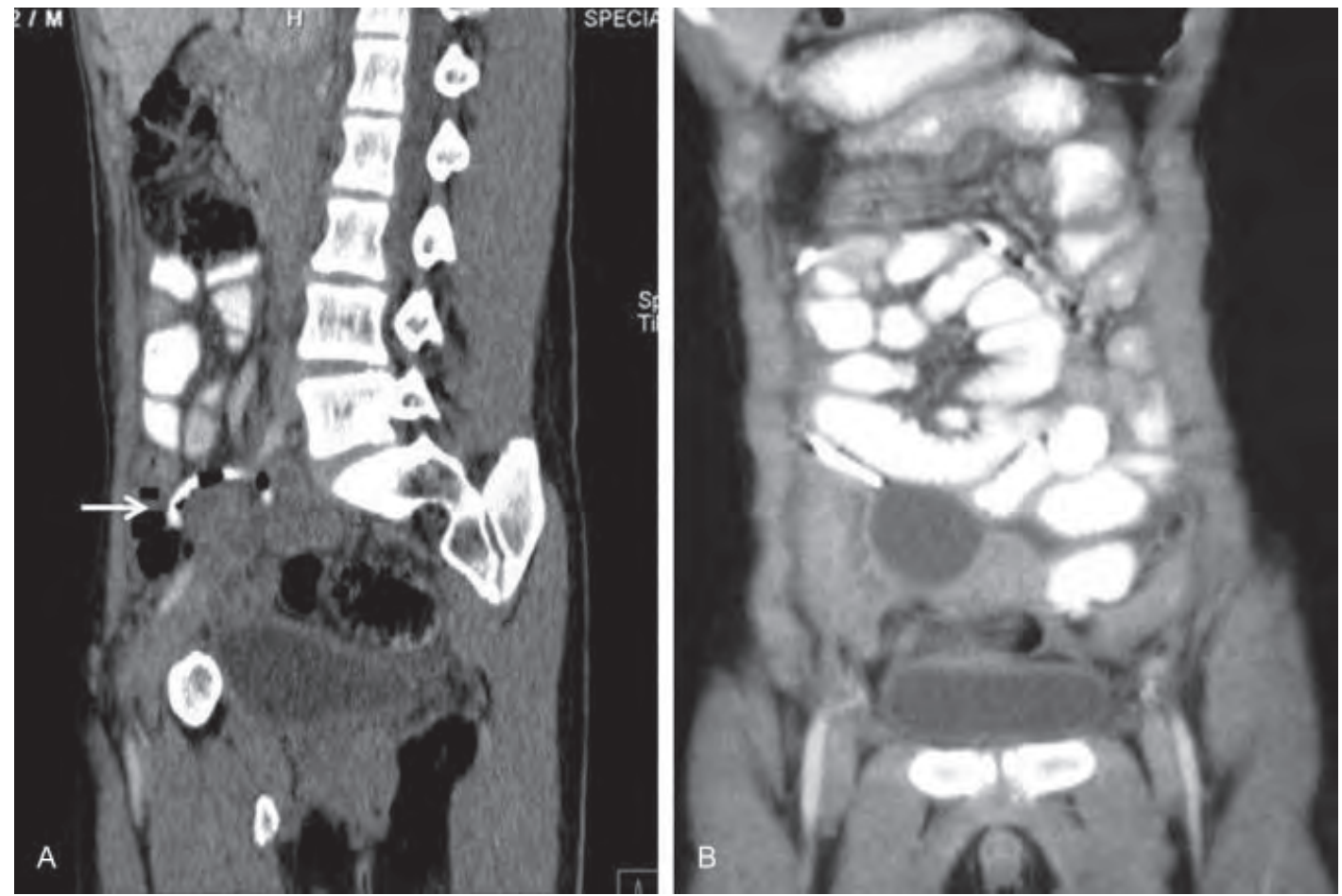

Fig. 19 (A, B) This 12-year-old male child had a few revisions of shunt, and in July 2007, since the catheter got blocked, it was removed and converted into a ventriculopleural shunt. The child was investigated with computed tomography for pain in the abdomen, which revealed localized fluid collection by the retained segment of the catheter in the abdomen. Air in retained piece of catheter (arrow) suggested perforation of the bowel wall, which was confirmed at surgery. The retained piece was removed. 

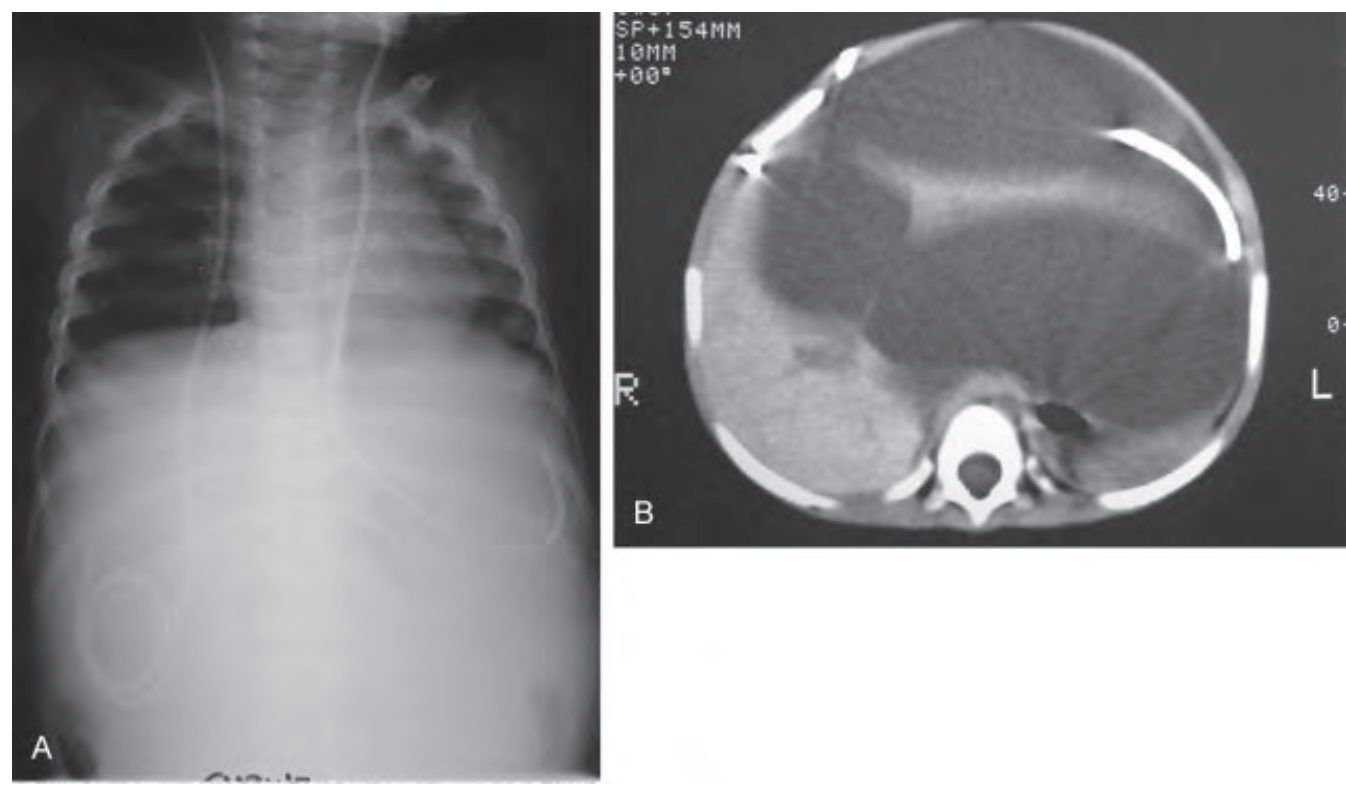

Fig. 20 (A, B) Bilateral ventriculoperitoneal (VP) shunts were placed in childhood in this child (left). A few months later, a palpable cystic mass was noted. Ultrasonography showed a large septate cyst with linear hyperechoic shadows. The computed tomography confirmed the cyst to have developed around the tips of both VP shunts (right).

- Enter into the processus vaginalis and then into the vulva. ${ }^{15}$ In this case report, the VP catheter was shown to enter into the vulva after passing through the patent processus vaginalis ( $\mathbf{- F i g . ~ 2 8 ) . ~}$

- Pierce the peritoneum and protrude into the umbilicus ${ }^{16}$ (-Fig. 29).

- Enter into the inguinal canal of a male child to form a hydrocele, as in the child show in - Fig. 30. ${ }^{17}$

- Pierce the rectum and extrude through the anus ( - Fig. 31A).

- Pierce the stomach and protrude through mouth, as reported in this case report ${ }^{5}(-$ Fig. 31B).

- Protrude into the heart or pulmonary artery by piercing the internal jugular vein. ${ }^{18}$

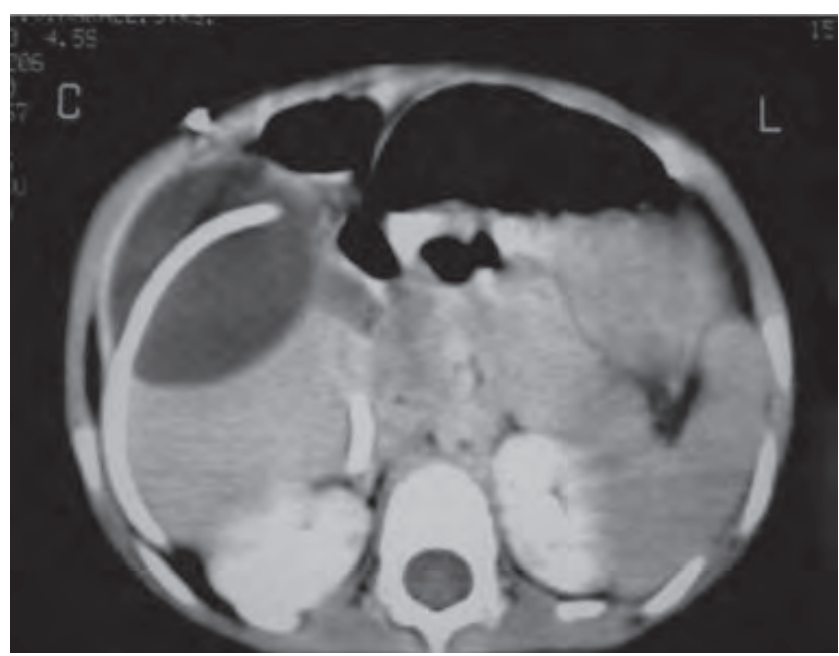

Fig. 21 This 3-year-old male child with congenital hydrocephalus developed a palpable cystic mass in upper abdomen on the right. On computed tomography, a pseudocyst around the catheter tip is shown mimicking as a liver cyst.
- It is also reported to perforate and enter into the gall bladder, liver, and tracheobronchial tree.

Retrograde spread of infection to the brain is an interesting complication. There are several case reports confirming the retrograde intracranial infection (ventriculitis) along the catheter after the tip of catheter had pierced the colon/rectum and had entered into its lumen.

Antegrade spread of malignant cells from brain tumor, such as a glioma, may occur to the peritoneal cavity through VPS. ${ }^{19}$

\section{Specific or Syndromic Complications}

These are as seen in - Table $\mathbf{3}$ and are elaborated as follows:

- Craniostenosis: this may be a cause or an association..$^{20}$ Postshunt craniostenosis is a result of apposition and overlapping of the cranial sutures in an infant following decompression of hydrocephalus (-Fig. 32). On the contrary, a shunt may be required in case of craniostenosis, as in cloverleaf skull, with aqueduct stenosis (-Fig. 33).

- Sunken skin flap syndrome (trephine syndrome, posthemicraniectomy, paradoxical herniation $)^{21}$ (-Fig. 34):

Table 3 Specific or syndromic complications

\begin{tabular}{|l|}
\hline Craniostenosis \\
\hline Sunken skin flap syndrome \\
\hline Trapped/isolated ventricle \\
\hline $\begin{array}{l}\text { Double ventricle syndrome or double compartment } \\
\text { syndrome }\end{array}$ \\
\hline Slit lateral ventricle syndrome in children \\
\hline
\end{tabular}




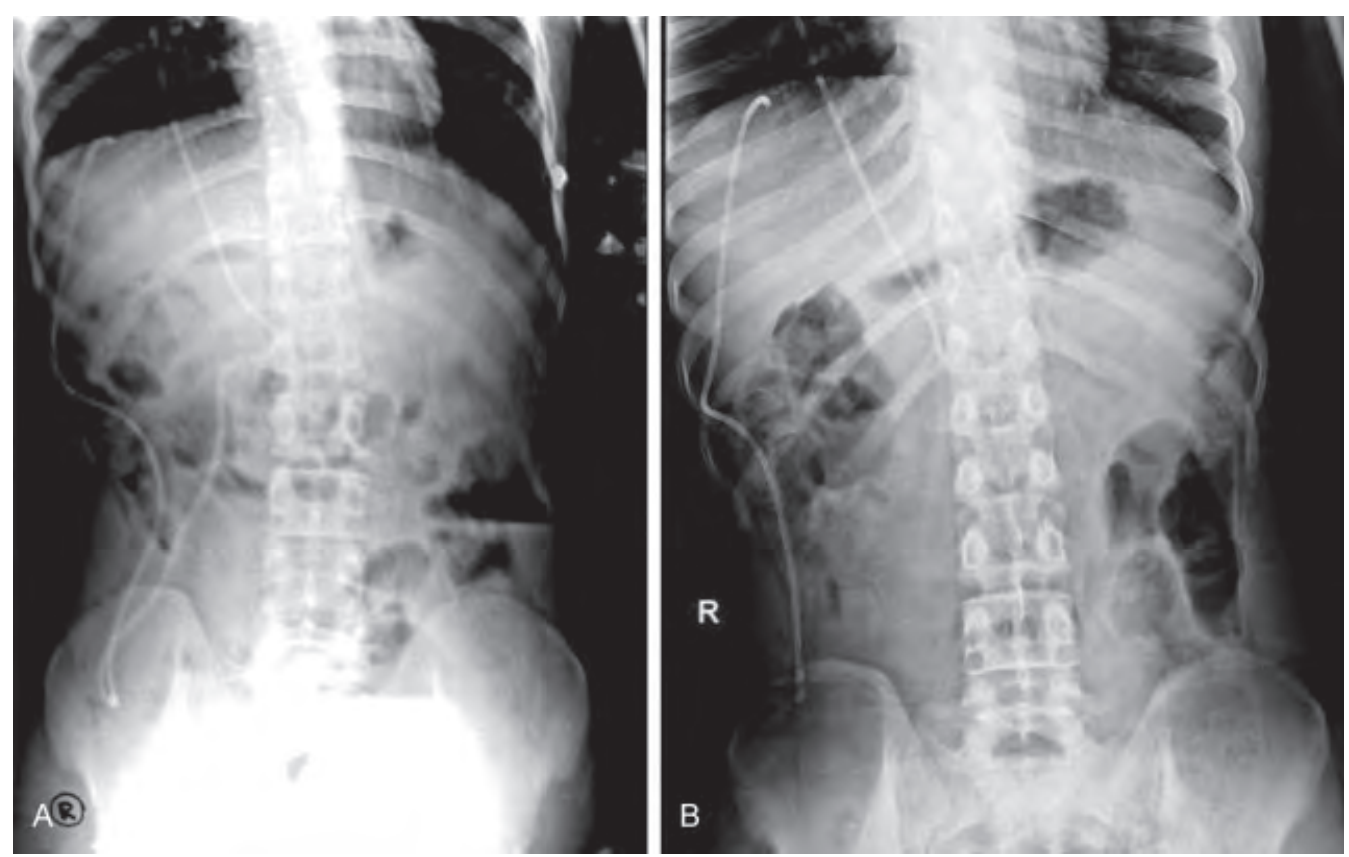

Fig. 22 (A, B) The peritoneal catheter is seen fractured in the image on the right.

internal or paradoxical herniation may occur in patients with a large craniotomy defect and CSF drainage by either lumbar puncture or VPS. There are orthostatic headache, depressed level of consciousness, autonomic instability, signs of brainstem release, and focal neurologic deficits. There is decrease in CSF pressure causing reduction in intracranial pressure, which may make intracranial content vulnerable to atmospheric pressure.

- СT: this may show midline shift with subfalcine, transtentorial, or uncal herniations in greater compression of brain.

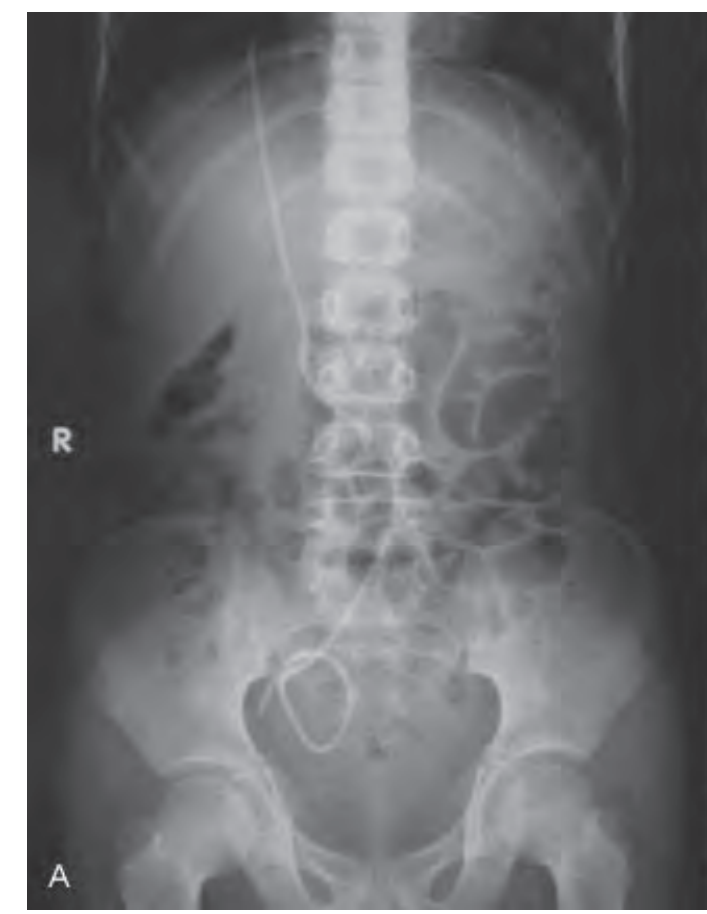

- Trapped/isolated ventricle: this happens in supratentorial compartment. After one lateral ventricle returns to normal size following VPS, the other gets dilated due to compression of foramina of Monro. This happens in the absence of infection. ${ }^{22}$

- Double ventricle syndrome or double compartment syndrome: this is a rare event after VP shunting for aqueduct stenosis. As the supratentorial ventricles return to normal size after shunting, the infratentorial fourth ventricle gets progressively dilated. The probable causes ${ }^{23}$ include obstruction of CSF

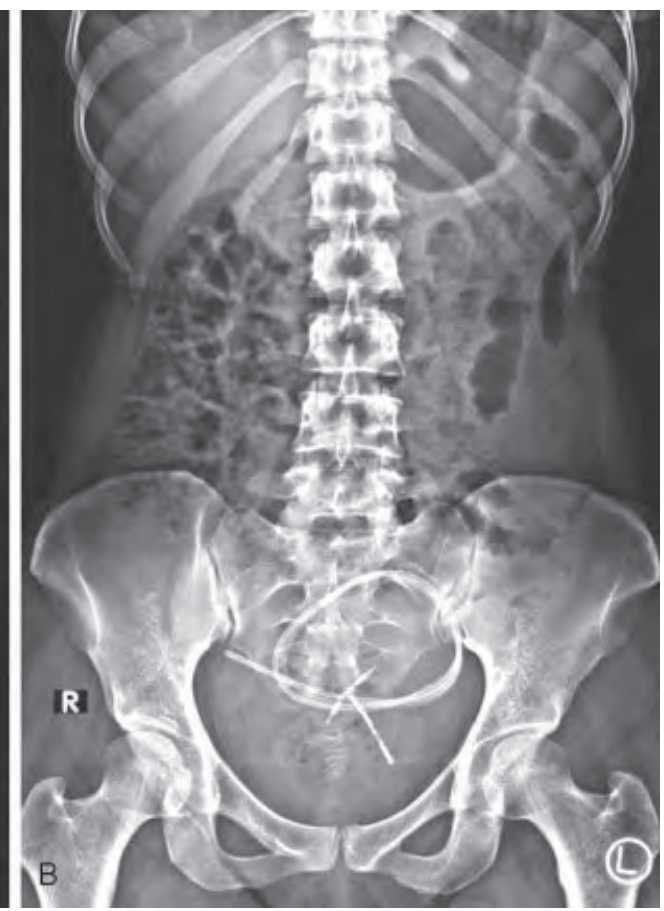

Fig. 23 (A, B) Coiled and knotted shunt catheters are seen in the abdomen and pelvis from old ventriculoperitoneal shunts. 

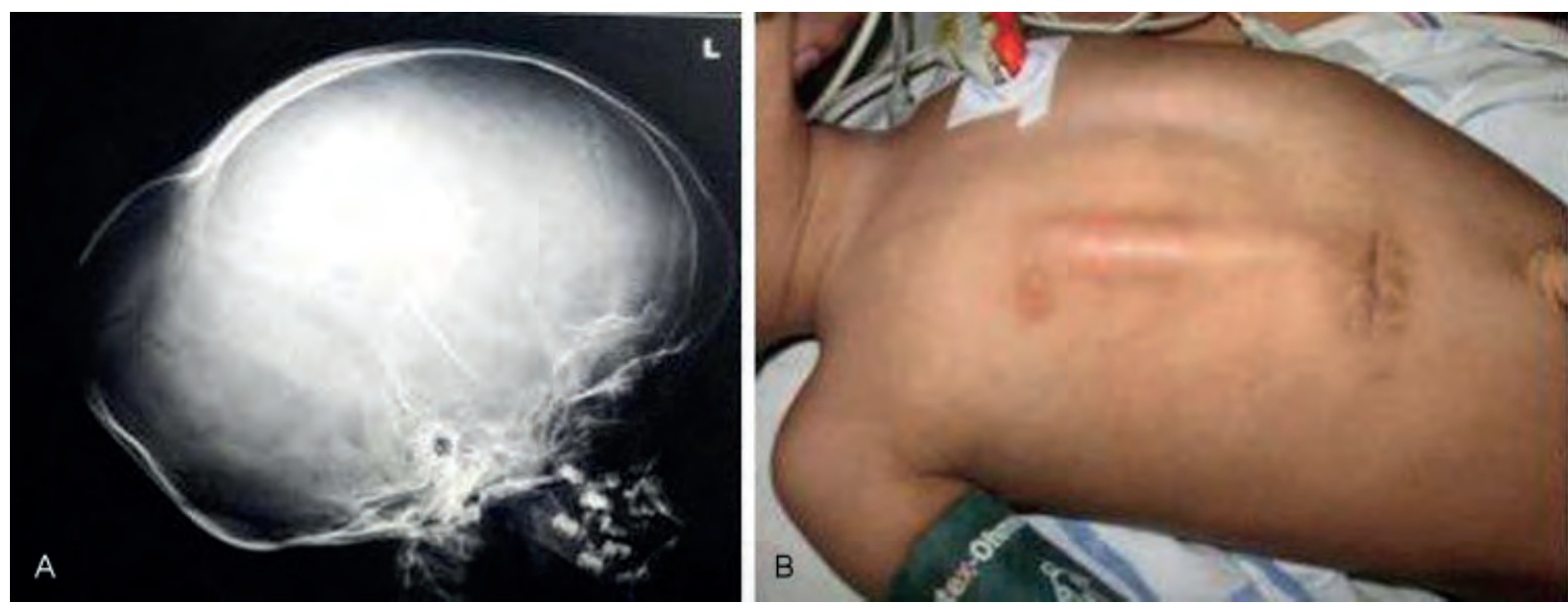

Fig. 24 (A, B) A palpable fluctuant swelling was noted along the course of ventriculoperitoneal (VP) catheter over right lower chest due to leakage of cerebrospinal fluid around the wall of the catheter. Sometimes, such leaks take a serpiginous shape. This 7-year-old child showed enlarged skull and focal bulging due to hydrocephalus due to malfunctioning of the VP shunt.
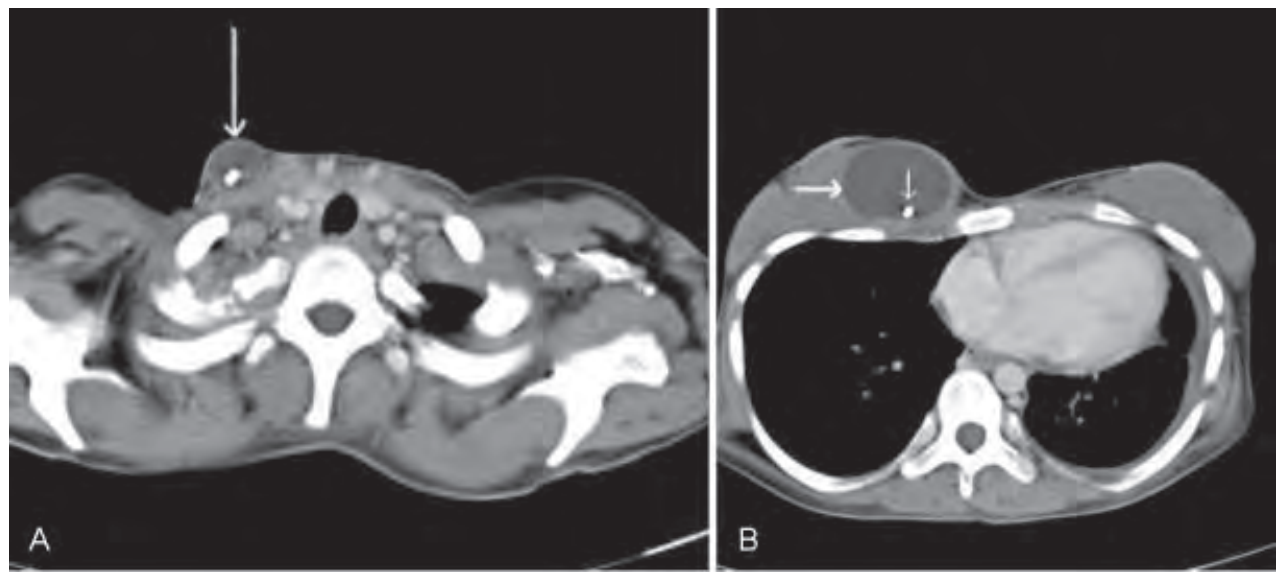

Fig. 25 (A, B) This young woman felt a mass in her right breast. The imaging showed that the ventriculoperitoneal catheter had retracted in the neck surrounded by leaked cerebrospinal fluid and had also settled behind the breast as a cystic mass. (Used with thanks and permission from Jakhere SG. $)^{12}$
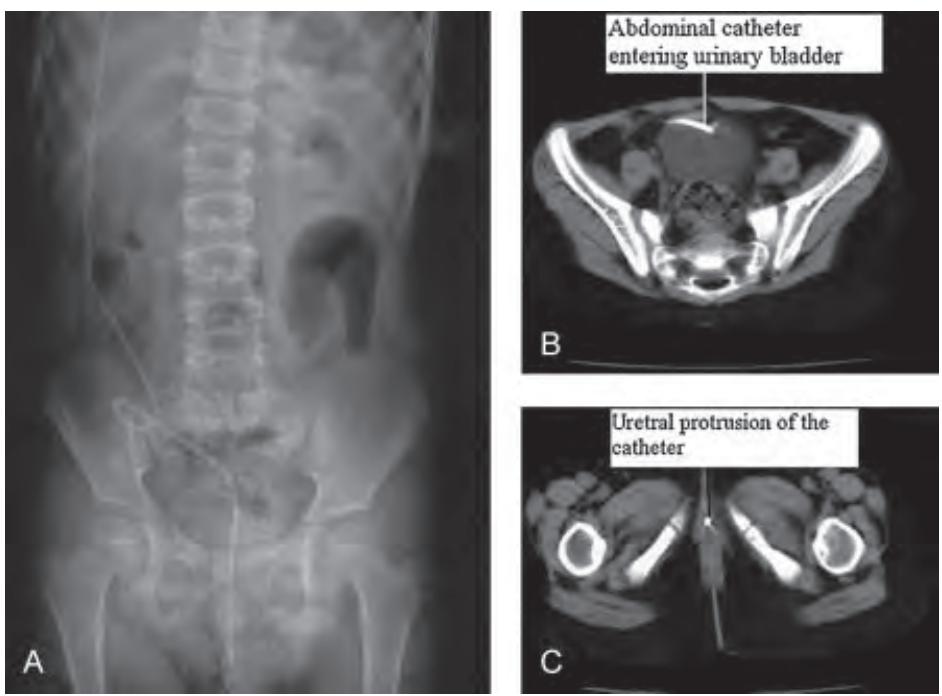

Fig. 26 (A-C) The peritoneal catheter has protruded into the bladder and urethra. Computed tomography images confirm this complication. (Used with thanks and permission from Kanat A. $)^{13}$

outflow at the outlet foramina of the fourth ventricle (Luschka and Magendie), basal cisterns, and arachnoid granulations near the sagittal sinus, or else it may be the continuation of obstruction that gave rise to aqueduct obstruction. As it is, and often it is, symptomatic (due to compression of various structures in the posterior 

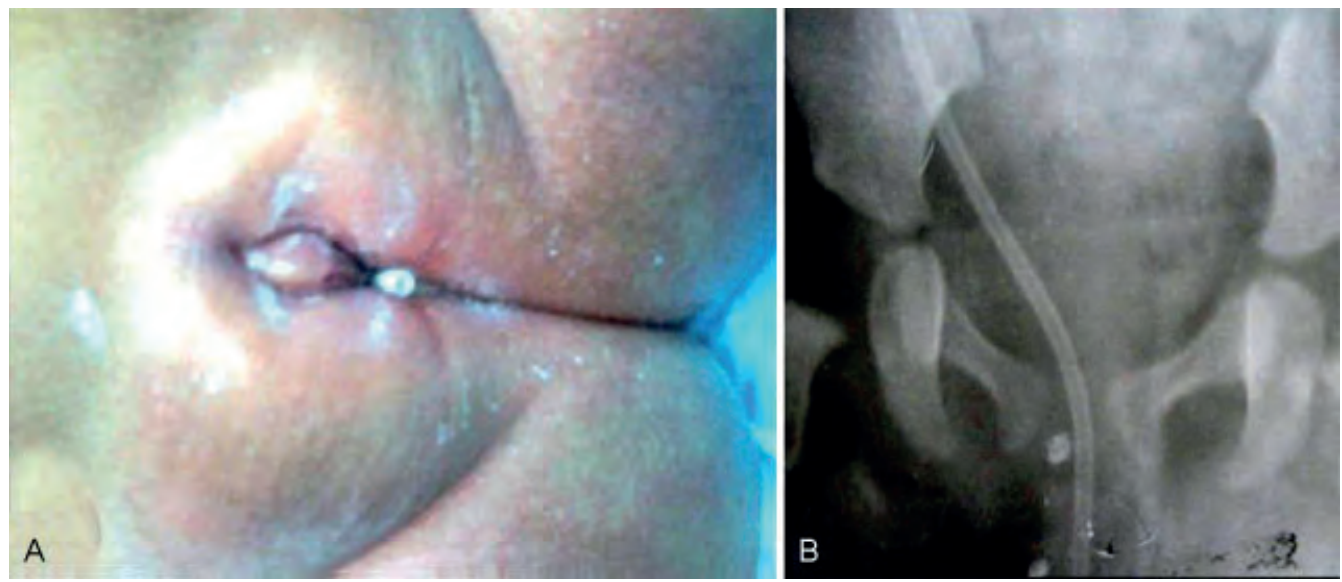

Fig. 27 (A, B) The photograph and computed tomography show catheter protruding into the vagina. The catheter had perforated the posterior wall of the vault of the vagina. (Used with thanks and permission from Teegala R.) $)^{14}$

fossa) additional shunting of the fourth ventricle becomes necessary, ${ }^{23}$ which relieves the patient of symptoms ( - Fig. $\mathbf{3 5}$ ).

- Slit lateral ventricle syndrome (SLVS) in children: this occurs in children due to rapid drainage of CSF. Ventricles look collapsed or slitlike, hence the name slit lateral ventricle syndrome. Clinically, there is picture of overdrainage of CSF with headache. Tonsils may prolapse. It may recur in a child again and again ${ }^{24}$ ( - Fig. 36).

- SLVS in adults or adolescents occurs in those who are shunted since childhood due to loss of compliance of ventricular walls. CSF slowly overdrains over several years, which is manifested by headache, varying degrees of lethargy, with or without nausea, and vomiting. Headache is severe, intermittent, characteristically lasting 10 to
90 minutes, and is often relieved when lying down or in prone position. ${ }^{25}$ Patients may be asymptomatic for prolonged periods ( - Fig. 37 ).

\section{Lastly: This Is an Eye-Opener Story ${ }^{23}$}

A patient with programmable shunt, who had become symptomatic with pressure setting of 0.5 , underwent MRI, which was normal. Next day the patient became comatose and acutely obtunded. The pressure setting had changed from 0.5 to 2.5, causing acute hydrocephalus, as seen on CT. MRI had induced alteration in valve setting of programmable shunt and worsened the clinical status. It is extremely important not to perform MRI in a patient with programmable shunt or to perform with only a precaution that pressure setting is checked/corrected soon after MRI.
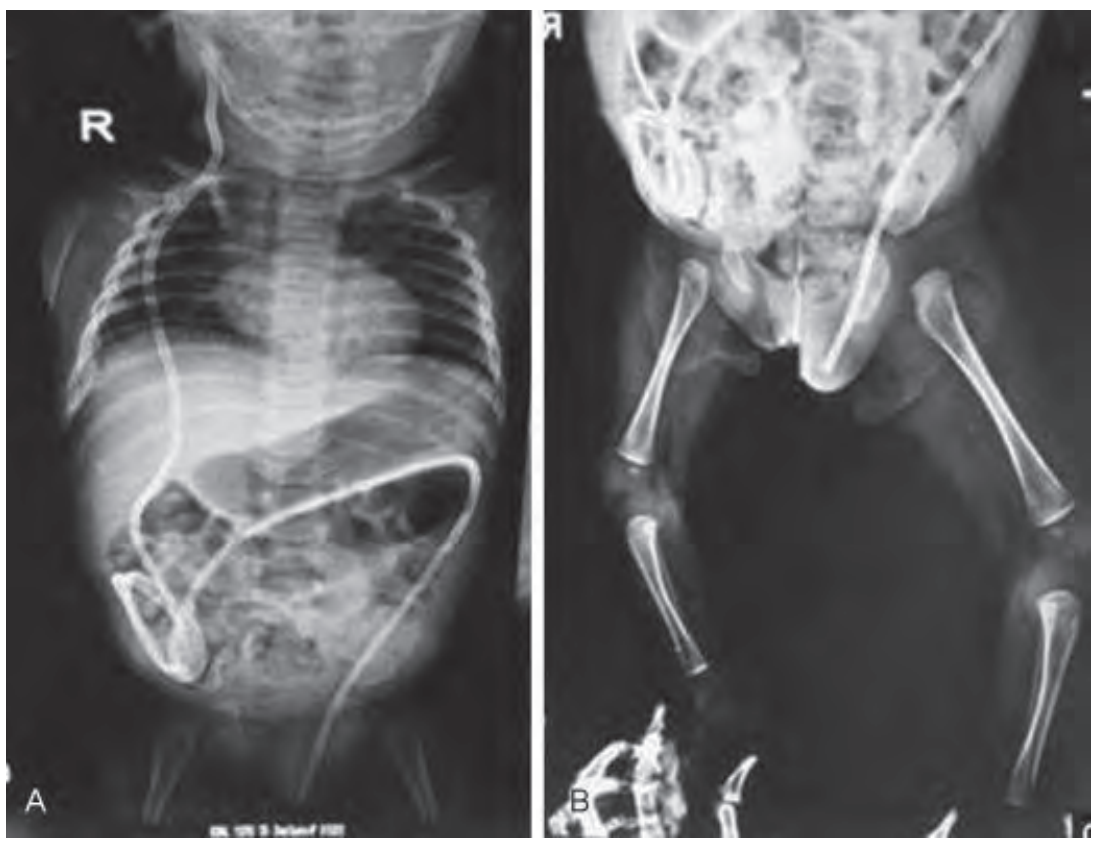

Fig. 28 (A, B) In this female child, the catheter is seen entering into the vulva and passing through the patent processus vaginalis. (Used with thanks and permission from Sharma M. $)^{15}$ 


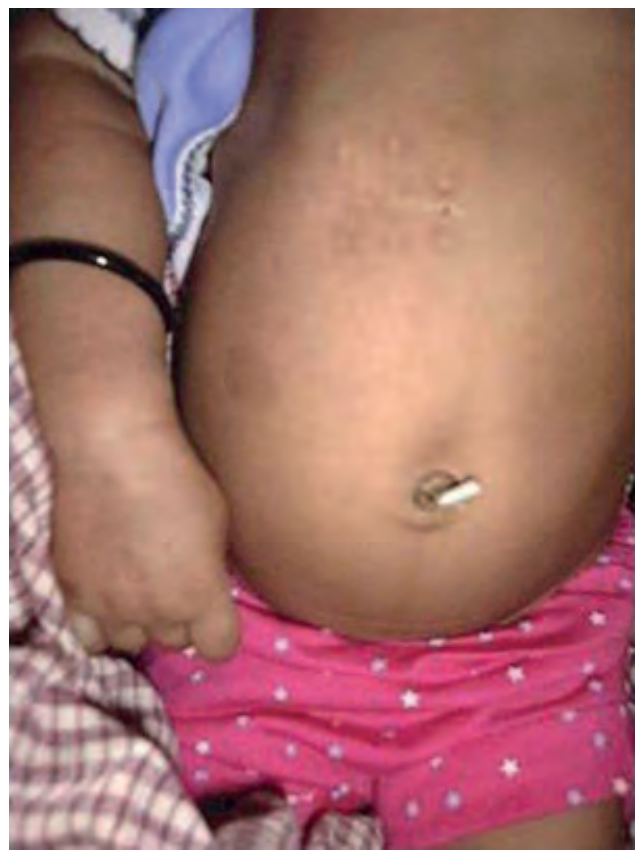

Fig. 29 The ventriculoperitoneal (VP) catheter is seen protruding into the umbilicus. (Used with thanks and permission from Sarkar D.) ${ }^{16}$ On pressing the shunt reservoir behind the ear, fluid started dribbling out of the tube protruding through the umbilicus, confirming the protruding end to be the distal end of the VP shunt. There are five ridges in the peritoneum that line the lower part of the anterior abdominal wall, which converge in the midline at the umbilicus. Peristaltic activities can thus direct foreign bodies, such as VP shunt catheter, in the peritoneal cavity toward the umbilicus and push it to come out.
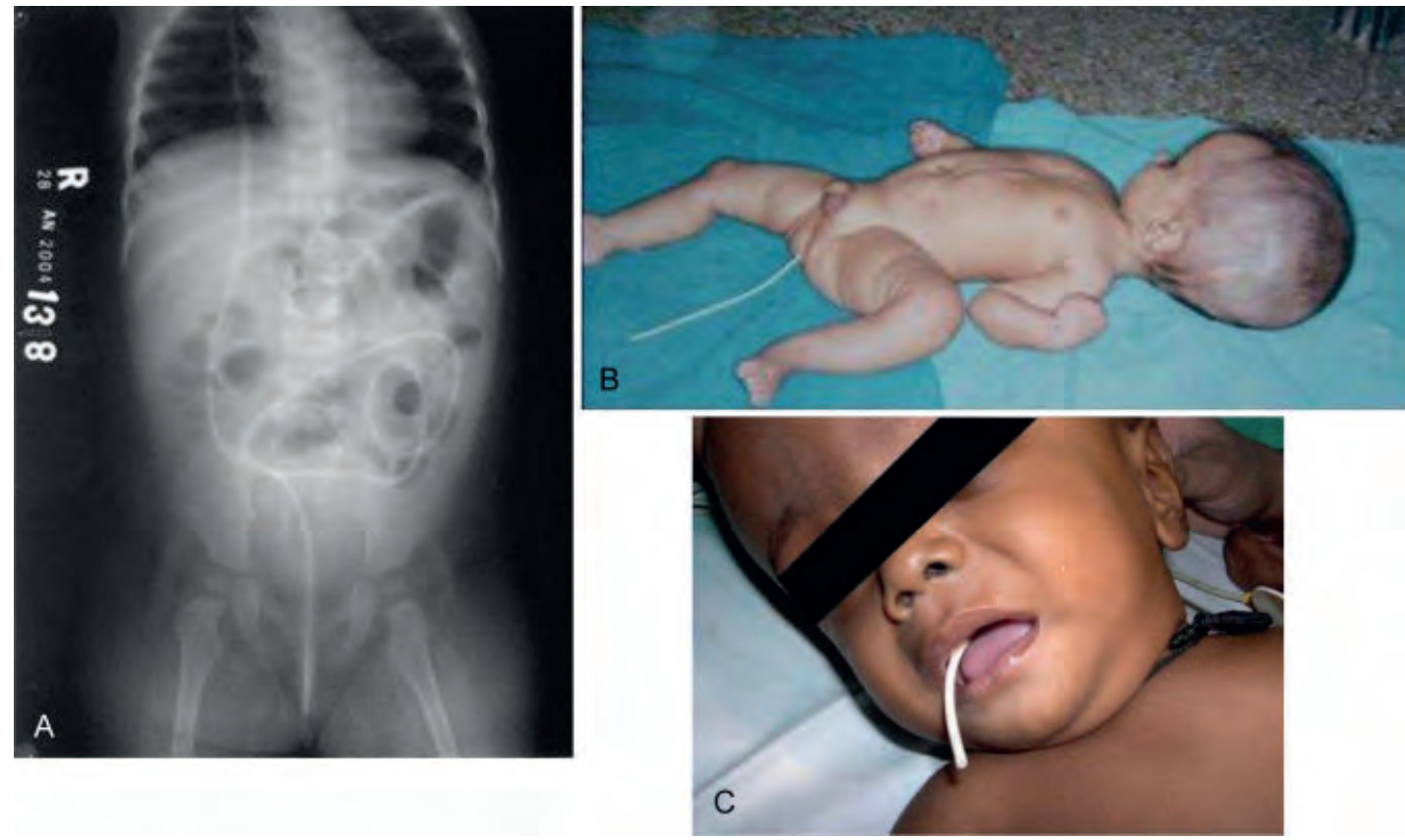

Fig. 31 (A, B) In this child, shunt catheter protruded through the anus by perforating the rectum. The course of the shunt catheter from the neck to the abdomen can be appreciated by a focal ridge of the skin. (C) The ventriculoperitoneal catheter protruded through the mouth after piercing the stomach. (Used with thanks and permission from Ahmed A.) $)^{5}$ 


\section{Conclusion}

The treatment of hydrocephalus over the years has been a great challenge for neurosurgeons not because of CSF dynamics but because of complications of employing different types of CSF diversion shunts. Shunt dependence with frequent shunt revisions has become the rule for most hydrocephalic children. Imaging with plain radiography, and CT are immensely useful tools to detect them, and therefore the dependence on these imaging techniques is ever increasing.

It is a truism to say that "once shunted is always shunted" and "no shunt procedure or type is absolutely safe"

\section{Funding}

None.

\section{Conflict of Interest}

None.

\section{Acknowledgments}

I am grateful to the clinical support from Dr. Ranjit Deshmukh, DNB, staff neurosurgeon, Sahyadri Hospital, Pune.

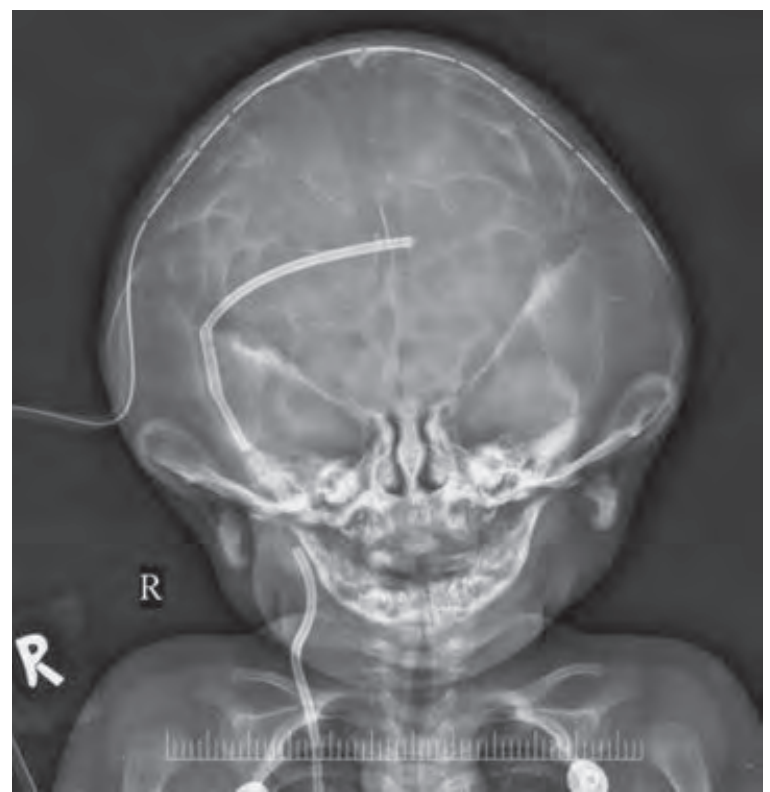

Fig. 33 This child had cloverleaf skull, a type of craniostenosis, and yet had congenital aqueduct stenosis. It was shunted for hydrocephalus. This is how a ventriculoperitoneal shunt and craniostenosis may become associated together.
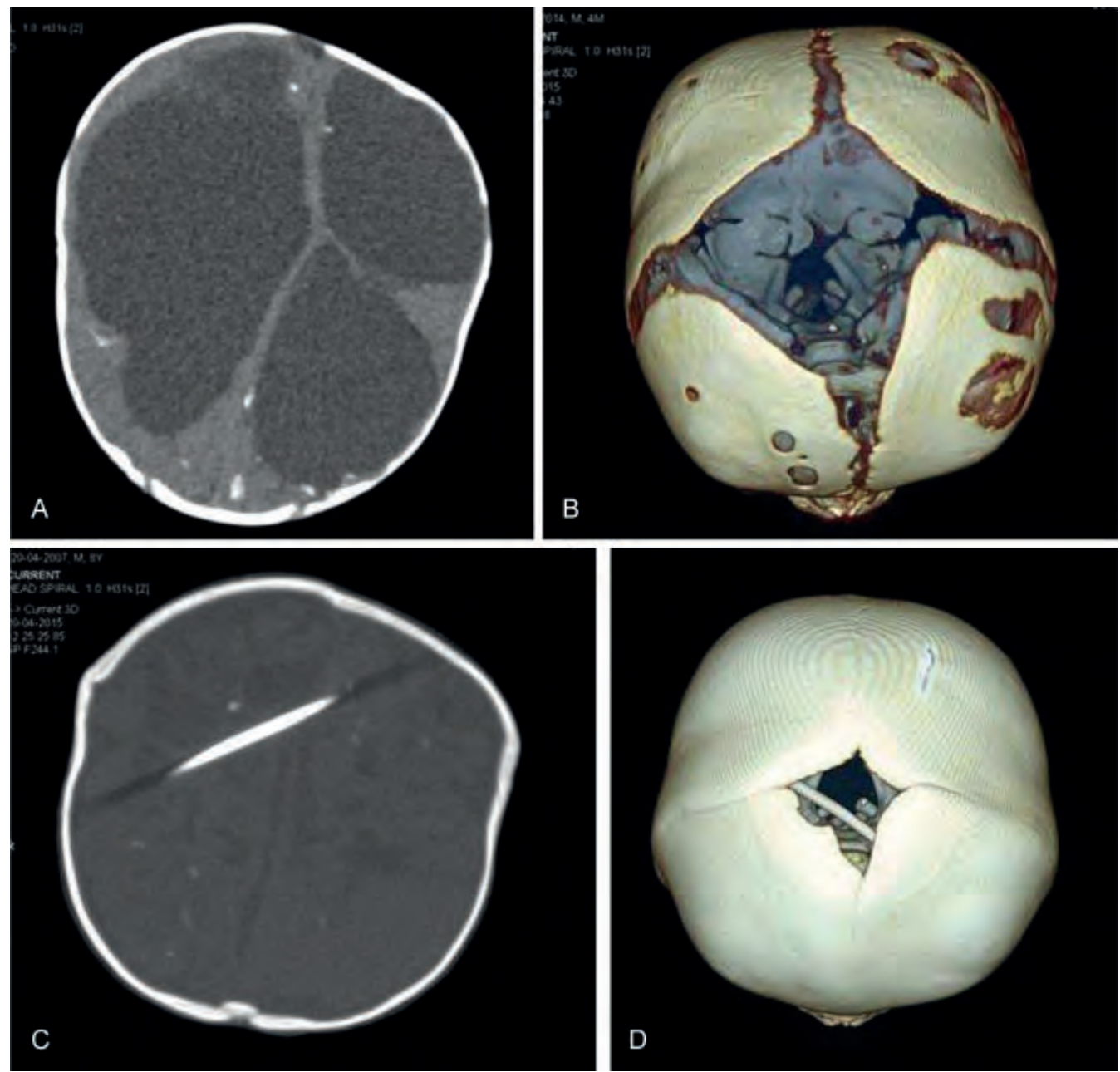

Fig. 32 (A-D) This male child was shunted at 2 months for postmeningitis hydrocephalus (top figures). Postshunt craniostenosis, as in this case, is the result of apposition and overlapping of the cranial sutures (bottom figures) in an infant following decompression of hydrocephalus. 

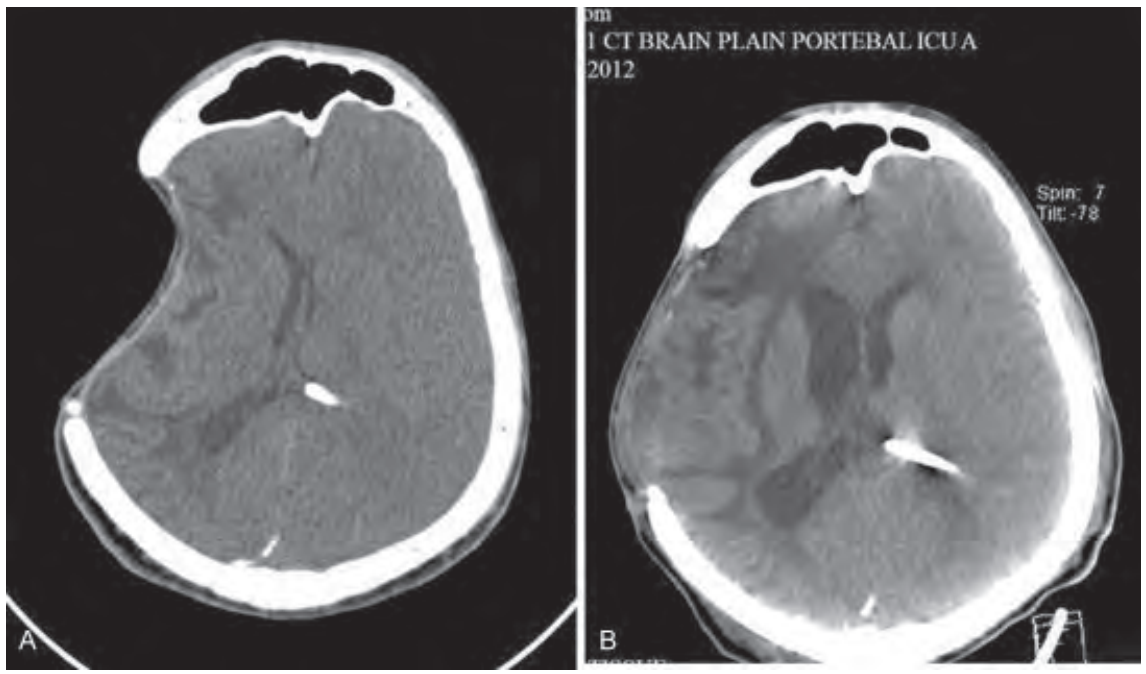

Fig. 34 (A, B) This adult male had ventriculoperitoneal (VP) shunt since childhood. He had required craniotomy later. He developed headache of short duration due to sunken flap syndrome due to rapid overdrainage of cerebrospinal fluid. Computed tomography shows sunken flap, collapsed ventricles, and a VP shunt in situ on the other side. After treatment, flap returned to its normal position, and the collapsed lateral ventricles regained their previous size (right).
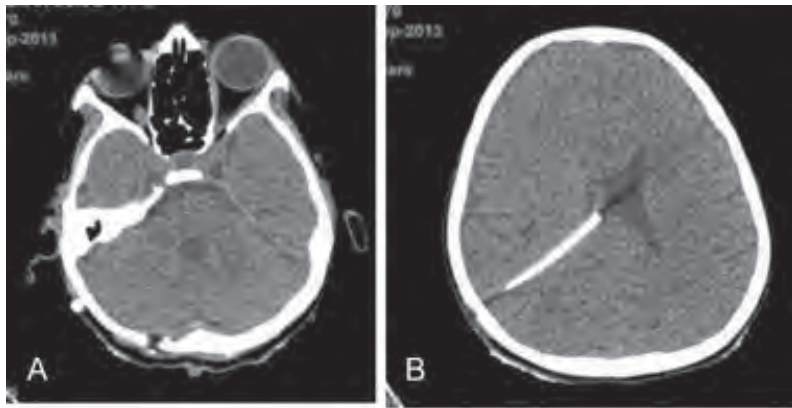

25-9-13
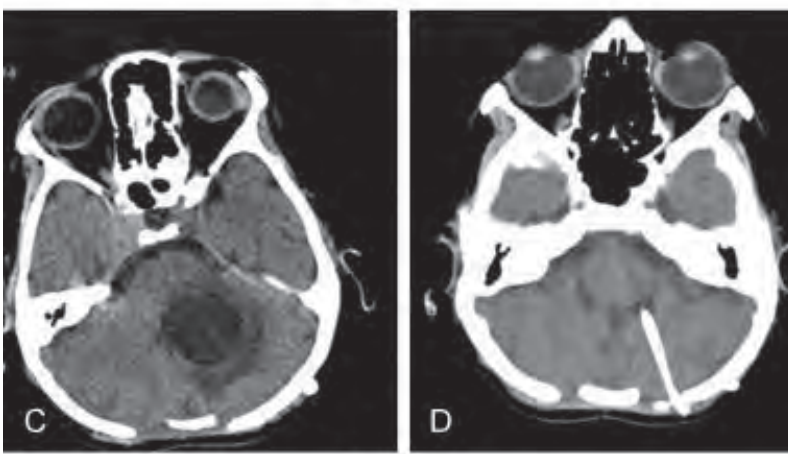

28-4-14

Fig. 35 (A-D) On September 25, 2013, this male, 14 years old, was operated for choroid plexus papilloma. As there was hydrocephalus, he was shunted. The lateral ventricles became normal, but within 7 months, the fourth ventricle showed progressive dilatation, as shown by two chronological computed tomography images. This is called by neurosurgeons as "double compartment syndrome." He was required shunting of fourth ventricle, which was done on April 28, 2014.

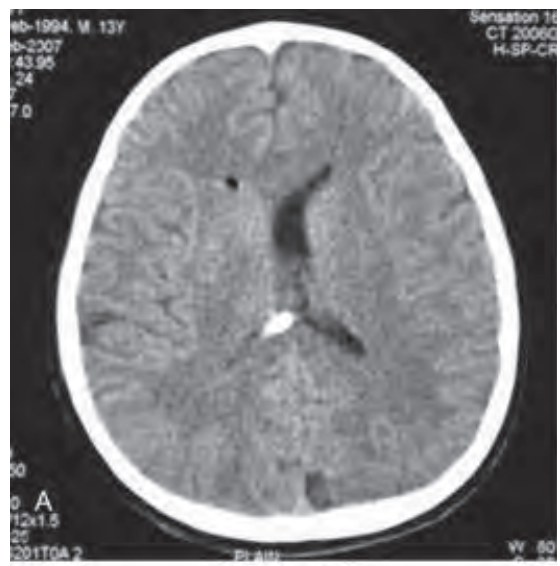

23-2-07

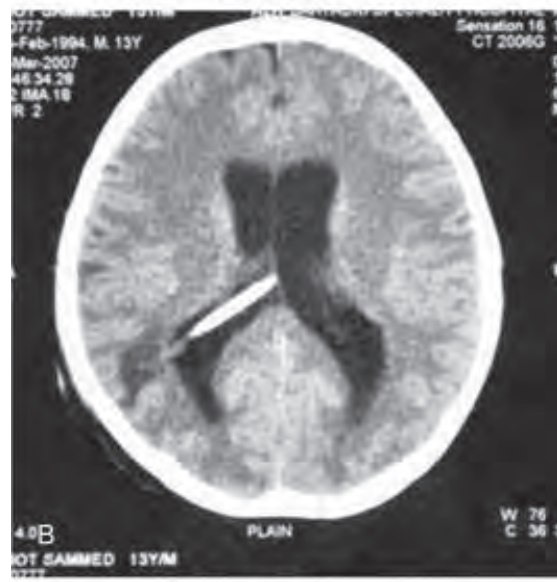

23-2-07

Fig. 36 (A, B) This 14-year-old male, who had been shunted in childhood, presented with symptoms of overdrainage with headache (February 23, 2007). Computed tomography showed collapsed ventricles, and after treatment, they opened the same day. This is typical of slit lateral ventricle syndrome. This can recur, as it did in this child. 


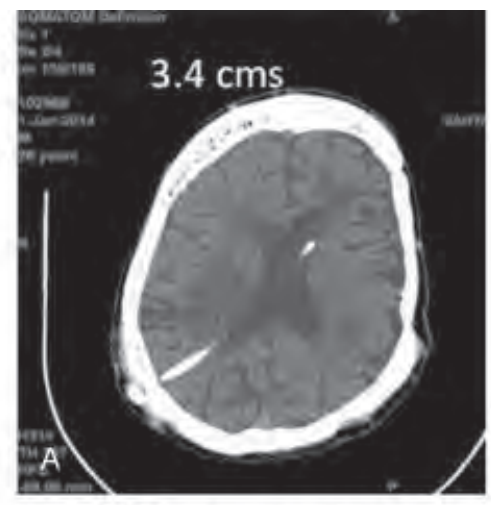

$1 / 1 / 14-$ shunt pressure
Raised to 200 on $1 / 1 / 14$

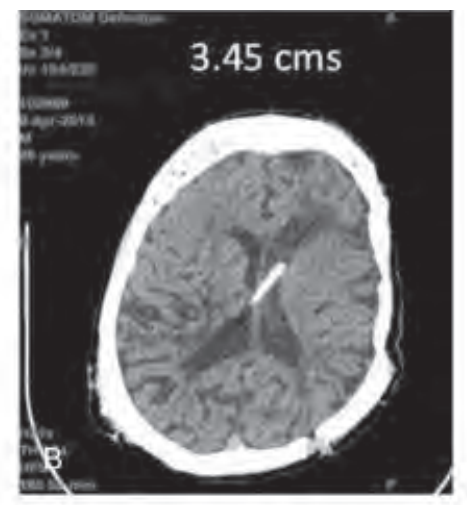

$9 / 4 / 14$ - shunt tied on $19 / 4 / 14$

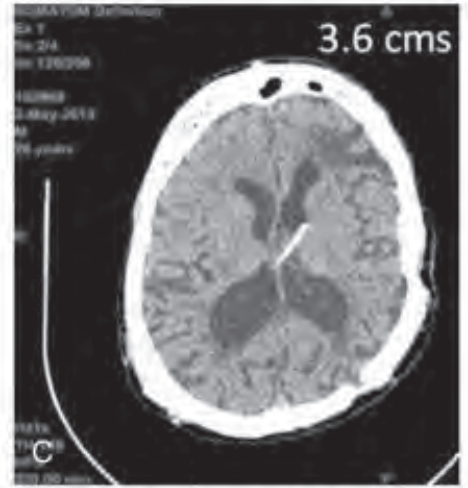

\section{3//5/14 anti siphon device added - marginal CT and clinical improvement}

Fig. 37 (A-C) This is an adult male, who had a ventriculoperitoneal shunt since childhood, which was revised several times. The shunt was changed to a programmable shunt, and the pressure reading was changed many times and finally to a maximum of $200 \mathrm{~mm}$. Still the ventricles remained collapsed and he was symptomatic. He was unable to stand longer than 30-40 minutes and got partial relief in head-low position. This is typical of slit lateral ventricle syndrome in an adult. He was treated by adding an antisiphon device, which gave him some relief. The ventricles opened up, and the symptoms were abated.

\section{References}

1 Aschoff A, Kremer P, Hashemi B, Kunze S. The scientific history of hydrocephalus and its treatment. Neurosurg Rev 1999;22(2-3): :67-93, discussion 94-95

2 Wallace AN, McConathy J, Menias CO, Bhalla S, Wippold FJ II. Imaging evaluation of CSF shunts. Am J Roentgenol 2014;202(01):38-53

3 Goeser CD, McLeary MS, Young LW. Diagnostic imaging of ventriculoperitoneal shunt malfunctions and complications. Radiographics 1998;18(03):635-651

4 Agarwal P, Malapure SM, Gupta R, Mane P, Parelkar S, Oak SN. Round worm migration along ventriculoperitoneal shunt tract: a rare complication. J Postgrad Med 2000;46 (01):37-38

5 Ahmed A, Sandlas G, Kothari P, et al. Outcome analysis of shunt surgery in hydrocephalus. J Indian Assoc Pediatr Surg 2009;14(3):98-101

6 Agrawal A, Rao GM. Subcutaneous shunt catheter calcification: an uncommon cause of shunt failure. Saudi J Med Med Sci 2014;2:125-126

7 Dube SK, Chowdhury T, Chaturvedi A. Anesthetic concerns in patients with abnormal migration of ventriculoperitoneal shunt. Saudi J Anaesth 2012;6 (01):76-77

8 Amans MR, Dillon WP. Cerebral parenchymal cyst: a rare complication of ventriculoperitoneal shunt malfunction in an adult. Radiol Case Rep 2015;8 (01):784

9 Chung JJ, Yu YS, Kim JH, Nam SJ, Kim MJ, et al. Intraabdominal complications secondary to ventriculoperitoneal shunts:
CT findings and review of the literature. Am J Roentgenol 2009;193 (05):1311-1317

10 Karapolat S, Onen A, Sanli A. Intrathoracic migration of ventriculoperitoneal shunt: a case report. Cases J 2008;1(01):42

11 Wang B, Hasadsri L, Wang H. Abdominal cerebrospinal fluid pseudocyst mimicking full-term pregnancy. J Surg Case Rep 2012;2012 (07):6

12 Jakhere SG, Kumbhar R. Unusual cause of breast lump: a CSF pseudocyst. Saudi J Radiol 2012;16:69-71

13 Yazar U, Kanat A, Akca N, Gazioglu G, Arda IS, Kazdal H. Urethral protrusion of the abdominal catheter of ventriculoperitoneal shunt: case report of extremely rare complication. J Pediatr Neurosci 2012;7 (02):111-113

14 Teegala R, Kota LP. Unusual complications of ventriculo peritoneal shunt surgery. J Neurosci Rural Pract 2012;3(03):361-364

15 Sharma M, Velho V, Mally R, Hrushikesh K. Vulvar migration of the peritoneal end through the inguinal canal in a female infant: an unusual complication of the ventriculo-peritoneal shunt: a case report and review of literature. J Pediatr Neurosci 2013;8 (01):67-69

16 Sarkar D, Sarkar S. Ventriculoperitoneal shunt catheter migration through umbilicus - A rare complication. Pediatriconcall.com Web site. http://www.pediatriconcall.com/ pediatric-journal/View/fulltext-articles/293/J/0/0/261/0. Accessed September 15, 2016

17 Ammar A, Ibrahim AW, Nasser M, Rashid M. CSF hydrocele-unusual complication of V-P shunt. Neurosurg Rev 1991;14 (02):141-143 
18 Rizk E, Dias MS, Verbrugge J, Boop FA. Intracardiac migration of a distal shunt catheter: an unusual complication of ventricular shunts. Report of 2 cases. J Neurosurg Pediatr 2009;3 (06):525-528

19 Lin Jang-Chun, Liu WH, Ma HI. Peritoneal metastasis of glioblastoma multiforme via ventriculo-peritoneal shunt. J Med Sci 2012;32 (04):179-182

20 Ryoo HG, Kim SK, Cheon JE, Lee JY, Wang KC, Phi JH. Slit ventricle syndrome and early-onset secondary craniosynostosis in an infant. Am J Case Rep 2014;15:246-253

21 Han PY, Kim JH, Kang HI, Kim JS. "Syndrome of the sinking skin-flap" secondary to the ventriculoperitoneal shunt after craniectomy. J Korean Neurosurg Soc 2008;43(01):51-53
22 Ginat DT, Westesson PL, eds. Trapped lateral ventricle. In: Atlas of Postsurgical Neuroradiology: Imaging of the Brain, Spine, Head and Neck. Berlin, Germany: Springer; 2012; 465

23 Foltz EL. Double compartment hydrocephalus. Wilkins RH, Rengachary SS. 2nd ed. New York, NYMcGraw Hill; 1996; 3665-3667

24 Benzel EC, Reeves JD, Kesterson L, Hadden TA. Slit ventricle syndrome in children: clinical presentation and treatment. Acta Neurochir (Wien) 1992;117(1-2): 7-14

25 Korfali E, Aksoy K, Safi I. Slit ventricle syndrome presenting with paroxysmal hypersomnia in an adult: case report. Neurosurgery 1988;22 (03): 594-595 